UNIVERSIDADE DE SÃO PAULO

FACULDADE DE MEDICINA DE RIBEIRÃO PRETO

WU ZHUOFAN

Proposta de um modelo de regressão binária com resposta contínua aplicado à análise dos dados do SINASC: identificação de fatores de risco para o baixo peso ao nascer

Versão corrigida

Ribeirão Preto

2011 


\section{Proposta de um modelo de regressão binária com resposta contínua aplicado à análise dos dados do SINASC: identificação de fatores de risco para o baixo peso ao nascer}

Versão corrigida. A versão original encontra-se disponível no Departamento de Medicina Social da Faculdade de Medicina de Ribeirão Preto da Universidade de São Paulo

Dissertação apresentada à Faculdade de Medicina de Ribeirão Preto da Universidade de São Paulo, programa de Pós-graduação em Saúde na Comunidade, para a obtenção do título de Mestre.

Área de Concentração: Saúde na Comunidade

Orientador: Prof. Dr. Edson Zangiacomi Martinez

Ribeirão Preto

2011 
AUTORIZO A REPRODUÇÃO E DIVULGAÇÃO TOTAL OU PARCIAL DESTE TRABALHO, POR QUALQUER MEIO CONVENCIONAL OU ELETRÔNICO, PARA FINS DE ESTUDO OU PESQUISA, DESDE QUE CITADA A FONTE.

\section{FICHA CATALOGRÁFICA}

Zhuofan, $\mathrm{Wu}$

Proposta de um modelo de regressão binária com resposta contínua aplicado à análise dos dados do SINASC: identificação de fatores de risco para o baixo peso ao nascer / Wu Zhuofan ; orientador Edson Zangiacomi Martinez. - Ribeirão Preto, 2011.

76 p.:il.; $30 \mathrm{~cm}$

Dissertação (Mestrado - Programa de Pós-graduação em Saúde na Comunidade) - Faculdade de Medicina de Ribeirão Preto da Universidade de São Paulo.

1. Modelos de regressão. 2. Estimação. 3. Bioestatística.

4. Peso ao nascer. 5. SINASC 


\section{FOLHA DE APROVAÇÃO}

Wu Zhuofan

Proposta de um modelo de regressão binária com resposta contínua aplicado à análise dos dados do SINASC: identificação de fatores de risco para o baixo peso ao nascer

Dissertação apresentada à Faculdade de Medicina de Ribeirão Preto da Universidade de São Paulo, Programa de Pós-graduação em Saúde na Comunidade, para a obtenção do título de Mestre.

Área de Concentração: Saúde na Comunidade

Aprovado em: 1 1

\section{BANCA EXAMINADORA}

Prof.(a) Dr.(a):

Instituição:

Assinatura:

Prof.(a) Dr.(a):

Instituição:

Assinatura:

Prof.(a) Dr.(a):

Instituição:

Assinatura: 


\section{DEDICATÓRIA}

\section{A Deus}

Aos meus pais Jianmin e Yueshan

Ao meu noivo Leandro

A toda minha família 


\section{AGRADECIMENTOS}

Ao meu orientador, Prof. Dr. Edson Zangiacomi Martinez, pelo entusiasmo, ajuda, reconhecimento, apoio e dedicação oferecidos no desenvolvimento deste trabalho.

Aos professores da minha banca de qualificação, pelas excelentes sugestões, que contribuíram muito para o aperfeiçoamento deste trabalho.

A todos os professores deste programa de Pós-graduação em Saúde na Comunidade, que tanto batalharam pela boa formação e crescimento científico dos seus alunos.

À Tânia, Paula, Carolina, Mônica, Regina, Solange e ao Sérgio do Departamento de Medicina Social, pela prontidão e apoio.

À Coordenação de Aperfeiçoamento de Pessoal de Nível Superior (CAPES), pelo auxílio financeiro. 


\title{
RESUMO
}

\begin{abstract}
ZHUOFAN, W. Proposta de um modelo de regressão binária com resposta contínua aplicado à análise dos dados do SINASC: identificação de fatores de risco para o baixo peso ao nascer. 2011. 76 f. Dissertação de mestrado (Saúde na Comunidade) - Faculdade de Medicina de Ribeirão Preto, Universidade de São Paulo, Ribeirão Preto, 2011.
\end{abstract}

O presente estudo tem por objetivo estudar a aplicabilidade de modelos de regressão binária com resposta contínua na análise de dados do SINASC (Sistema de Informações de Nascidos Vivos), analisando suas vantagens, limitações e estratégias na estimação de parâmetros ao identificar os fatores de riscos para baixo peso ao nascer. Muitos autores vêm utilizando os dados do SINASC para estudar as variáveis que estão associadas ao baixo peso ao nascer. Estes autores geralmente utilizam o modelo usual de regressão logística, o qual analisa somente respostas binárias (a variável resposta é codificada como 1: baixo peso ao nascer, 0: caso contrário). O modelo de regressão com resposta contínua foi utilizado para estudar as variáveis associadas aos recém-nascidos com maior propensão a um peso ao nascer inferior ao ponto de corte $2500 \mathrm{~g}$, ou seja, a resposta é expressa em uma va-riável contínua. Nesta situação, uma extensão do modelo tradicional foi utilizada visando a possibilidade de obter-se estimativas mais precisas. Para a estimação de parâmetros do modelo de regressão binária com resposta contínua, foi utilizado o método da má-xima verossimilhança. Os resultados obtidos a partir da metodologia proposta possui as seguintes vantagens em relação ao modelo usual: (a) o modelo de regressão proposto foi capaz de predizer o baixo peso ao nascer com maior precisão; (b) o modelo proposto evita problemas de separação persistentes em modelos usuais. Desta forma, o modelo estudado poderá oferecer significativas contribuições à Saúde Coletiva, ao trazer uma nova possibilidade de análise de dados desta área.

Palavras-chave: Modelos de regressão. Estimação. Bioestatística. Peso ao nascer. SINASC. 


\begin{abstract}
ZHUOFAN, W. A Propose of a Binary Regression Model with Continuous Response Applied to Data Analysis from SINASC: identification of risk factors for low birth weight. 2011. 76p. Dissertation (master degree), Faculdade de Medicina de Ribeirão Preto, Universidade de São Paulo, Ribeirão Preto, 2011.
\end{abstract}

The objective of this dissertation is to study the applicability of binary regression models for continuous outcomes in the data analysis from SINASC (Brazilian Live Births Information System), analyzing its advantages, limitations and strategies in the estimation of parameters, when identifying the risk factors for low-birth-weight. Many authors have been using data from SINASC to study the variables that are associated with the low-birth-weight. These authors typically use the usual logistic regression model, which analyzes only binary responses (the dependent variable is coded as 1 for low-birth-weight and 0 for otherwise). The regression model with continuous response was proposed and used to study the variables associated with the newborns with higher propensity to a birth weight below the cutoff point of $2500 \mathrm{~g}$, that is, the answer is expressed as a continuous variable. In this situation, an extension method of the traditional model was used in order to enable obtaining more accurate estimates. For the estimation of the parameters from binary regression model with continuous response, the maximum likelihood method was used. The results obtained from the proposed methodology brought these following advantages comparing with the usual model: (A) the proposed regression model was capable for predicting low birth weight with a bettter precision; (B) the proposed model can process the persistent problems of separation present in the conventional models. Thus, the studied method may offer significant contributions to the Public Health, bringing new possibilities for data analysis in this area.

Keywords: Regression models. Estimation. Biostatistics. Birth weight. SINASC. 


\section{LISTA DE FIGURAS}

1 Percentual de BPN de mães nas diferentes faixas etárias, SINASC de Ribeirão Preto em 2005 . . . . . . . . . . . . . . . . . . . . . 27

2 Distribuição de valores de $\beta_{0}, \beta_{1}$ e $\ln L\left(\beta_{0}, \beta_{1}, \sigma=0,645136\right)$. . . . . . . . 47

3 Contorno de $\beta_{0}$ versus $\beta_{1}$ para os valores de logaritmo de $L(\beta, \sigma) \ldots$. . . 48

4 Histograma do peso ao nascer, SINASC - Ribeirão Preto (2005) . . . . . . . 52

5 Box plot do PN em relação à situação conjugal e escolaridade da mãe, ao tipo de parto e se é primípara, SINASC - Ribeirão Preto (2005) . . . . . . 53

6 Box plot do PN de acordo com a duração da gestação, o número de consultas pre-natais, a raça e o sexo do RN, SINASC - Ribeirão Preto (2005) . 54

7 Box plot do PN referente à faixa etária da mãe, SINASC - Ribeirão Preto

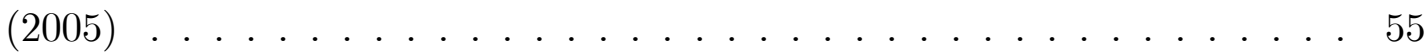

8 Gráfico de resíduos na análise de dados utilizando a regressão linear múltipla, SINASC - Ribeirão Preto (2005) _ . . . . . . . . . . . . . . . . 59

9 Curva ROC na comparação de métodos de estimativa com a regressão logística usual e a proposta no projeto. O mesmo conjunto de dados foi utilizado na estimativa e na obtenção da curva ROC . . . . . . . . . . . . 63

10 Curva ROC elaborada para a comparação entre a regressão usual e a proposta no projeto. A curva ROC foi obtida utilizando o conjunto de dados diferente daquele utilizado na estimação . . . . . . . . . . . . . . . . . 65 


\section{LISTA DE TABELAS}

1 Probabilidades condicionais $P(Y=y \mid X=x)$, onde $X$ é uma variável binária. . . . . . . . . . . . . . . . . 37

2 Peso ao nascer, de uma amostra de 50 recém-nascidos dos municípios Rio Branco e Feijó (AC), segundo tipo de parto $(\mathrm{X}=1$, parto vaginal, $\mathrm{X}=0$, parto cesariano . . . . . . . . . . . . . . . 46

3 Resultados da regressão logística usual para dados do SINASC de Ribeirão Preto, $2005 \ldots \ldots \ldots \ldots \ldots$. . . . . . . . . . . . . . . 57

4 Resultados da regressão binária com resposta contínua para dados do SINASC de Ribeirão Preto, 2005 . . . . . . . . . . . . . . . . . . . . . . 58

5 Resultados da regressão linear múltipla para dados do SINASC de Ribeirão

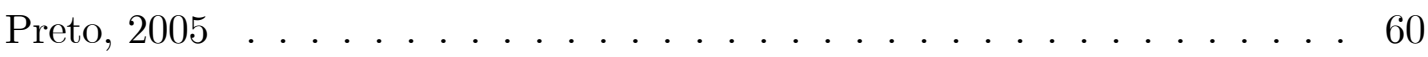

6 Resultados da regressão logística e da regressão com resposta contínua para dados do SINASC de Ribeirão Preto excluindo a variável "duração da gestação", 2005. . . . . . . . . . . . . . . . . . . . . . . 61 


\title{
LISTA DE ABREVIATURAS E SIGLAS
}

\author{
AIC..... Akaike's Information Criterion \\ AUC.... Area under the curve \\ BIC.... Bayesian information criterion \\ BPN.... Baixo peso ao nascer \\ CID-10.... Classificação internacional de doenças e problemas relacionados à saúde, \\ versão 10
}

DATASUS.... Departamento de informática do SUS

DIC.... Deviance information criterion

DN.... Declaração de nascido vivo

IBGE.... Instituto Brasileiro de Geografia e Estatística

IC..... Intervalo de confiança

IMC..... Índice de massa corporal

MCMC.... Monte Carlo em cadeia de Markov

MS.... Ministério da Saúde

MV..... Máxima verossimilhança

NLP..... Nonlinear programming

OMS..... Organização Mundial de Saúde

OR.... Odds ratio

PN..... Peso ao nascer

RIPSA..... Rede Interagencial de Informações para a Saúde

ROC..... Receiver operation curve

RR..... Risco relativo

SIA..... Sistema de Informações Ambulatoriais

SIAB.... Sistema de Informações sobre Atenção Básica

SIH.... Sistema de Informações Hospitalares

SIM..... Sistema de Informações sobre Mortalidade

SINAN..... Sistema de Informação de Agravos de Notifiação

SINASC.... Sistema de Informações de Nascidos Vivos

SIOPS.... Sistema de Informações de Orçamentos Públicos em Saúde

SIS.... Sistema de Informações

SUS.... Sistema Único de Saúde 


\section{SUMÁRIO}

1 INTRODUÇÃO 12

1.1 JUSTIFICATIVA . . . . . . . . . . . . . . . . 15

1.2 TRABALHOS RELACIONADOS . . . . . . . . . . . . . 17

2 OBJETIVO 21

2.1 OBJETIVO PRINCIPAL . . . . . . . . . . . . . . . . . 21

2.2 OBJETIVOS SECUNDÁRIOS . . . . . . . . . . . . . . 21

3 METODOLOGIA $\quad 22$

3.1 PRINCIPAIS FATORES DE RISCO PARA BPN IDENTIFICADOS NA LITERATURA . . . . . . . . . . . . . . . . . . . 22

3.2 BANCO DE DADOS . . . . . . . . . . . . . . . . . . 24

3.3 QUESTÕES ÉTICAS . . . . . . . . . . . . . . . . . . . . . . . 29

3.4 REGRESSÃO LOGÍSTICA USUAL . . . . . . . . . . . . . . . . . . 29

3.4 .1 O modelo múltiplo . . . . . . . . . . . . . . . . . . . 33

3.4 .2 Erros padrão . . . . . . . . . . . . . . . 34

3.4.3 Medidas de ajuste e comparação entre modelos . . . . . . . 35

3.4.4 Estimativa do odds ratio . . . . . . . . . . . . . . . . . . . . 37

3.5 REGRESSÃO BINÁRIA COM RESPOSTA CONTÍNUA . . . . . . . . . . 38

3.5.1 Função de ligação logito . . . . . . . . . . . . . . . . . . . 42

3.5.2 Função de ligação logarítmica . . . . . . . . . . . . . . . . . . 43

3.5.3 Função de ligação identidade . . . . . . . . . . . . . . . . . . 44

3.6 CURVA ROC . . . . . . . . . . . . . . . . . . . . 44

3.7 IMPLEMENTAÇÃOO . . . . . . . . . . . . . . . . . . . 46

3.8 EXEMPLOS DA ESTIMAÇÃO POR MÁXIMA VEROSSIMILHANÇA . . 46

3.8.1 Exemplo com amostra de dados de RN . . . . . . . . . . . . 46

3.8.2 Exemplo com dados simulados . . . . . . . . . . . . . . . . 49

4 RESULTADOS $\quad 51$

5 CONCLUSÃO $\quad 67$

$\begin{array}{llr}6 & \text { TRABALHOS FUTUROS } & 69\end{array}$

$\begin{array}{ll}\text { REFERENNCIAS } & 71\end{array}$

$\begin{array}{ll}\text { ANEXO A } & 75\end{array}$ 


\section{INTRODUÇÃO}

Uma tarefa importante e essencial na Saúde Coletiva é a realização de uma análise objetiva da situação sanitária populacional, assim como atividades de tomadas de decisões e/ou avaliações de estratégias e ações de saúde pública. Para alcançar esse objetivo de análise e busca de medidas da situação contemporânea de saúde da população, instrumentos como indicadores de saúde são requisitados visando facilitar a sistematização dos dados coletados (REDE INTERAGENCIAL DE INFORMAÇÕES PARA A SAÚDE RIPSA, 2002). Os indicadores de saúde, quando gerados, utilizados e interpretados adequadamente, produzem informações sobre situações reais e tendências prováveis de saúde. Consequentemente, eles servem de referência para o estabelecimento de estratégias melhor ajustadas às necessidades da saúde pública, além de favorecer o desenvolvimento de sistemas de informação em saúde.

Apesar da importância dos indicadores de saúde, estes, sem suporte de um sistema de armazenamento e gerenciamento de dados confiáveis e de coleta contínua, não poderiam cumprir suas funções na gestão em saúde. O desenvolvimento de sistemas de informação em saúde oferece bases de dados que servirão de evidências científicas para suporte gerencial nas tomadas de decisões. Segundo a Organização Mundial de Saúde (OMS) (1988), um Sistema de Informação em Saúde (SIS) é:

"[...] um mecanismo de coleta, processamento, análise e transmissão da informação necessária para se organizar e operar os serviços de saúde e, também, para a investigação e o planejamento com vistas ao controle de doenças. $O$ propósito é selecionar os dados pertinentes aos serviços de saúde e transformálos na informação necessária para o processo de decisões, próprio das organizações e indivíduos que planejam, financiam, administram, provêem, medem e avaliam os serviços de saúde."

Dessa forma, um SIS deve ser considerado como um instrumental que facilita o estabelecimento do conhecimento da realidade em saúde, tornando mais eficiente o processo 
de planejamento, gestão e avaliação das decisões de saúde.

Nas últimas décadas, vários importantes SISs nacionais foram desenvolvidos e seus dados divulgados eletronicamente pelo Ministério da Saúde (MS). Dados relacionados com nascimentos (Sistema de Informações de Nascidos Vivos - SINASC), óbitos (Sistema de Informações sobre Mortalidade - SIM), doenças de notificação (Sistema de Informação de Agravos de Notificação - SINAN), atendimentos hospitalares (Sistema de Informações Hospitalares - SIH), atendimentos ambulatoriais (Sistema de Informações Ambulatoriais SIA), atenção básica (Sistema de Informações sobre Atenção Básica - SIAB), orçamentos públicos em saúde (Sistema de Informações de Orçamentos Públicos em Saúde - SIOPS) são importantes em pesquisas de Saúde Pública (REDE INTERAGENCIAL DE INFORMAÇÕES PARA A SAÚDE - RIPSA, 2002).

Os dados de nascidos vivos e de mortalidade são essenciais para estabelecer determinantes epidemiológicos e demográficos da morbidade e mortalidade da criança e da mulher, além de possibilitar o planejamento e a avaliação das ações de saúde da criança no Sistema Único de Saúde (SUS). Esses dados são continuamente coletados e divulgados pelo MS através do SIM e do SINASC (SOUZA et al., 2004). Assim, foram utilizadas informações provenientes do SINASC no desenvolvimento desta pesquisa.

O SINASC foi implantado pelo MS em 1990, tendo como objetivo de registrar, em âmbito nacional, informações de nascidos vivos de forma sistemática (CARVALHO, 1997). As bases de dados do sistema somente estiveram disponíveis no site do Departamento de informática do SUS (DATASUS) a partir de 1994. O Registro Civil tem como objetivo principal a quantificação de nascidos registrados, enquanto que o SINASC é direcionado para a caracterização das condições de nascimento (MELLO-JORGE et al., 1996). Esperase que no SINASC a qualidade da informação seja mais confiável e a cobertura seja maior que a do Registro Civil, pois a Declaração de Nascido Vivo (DN), documento que alimenta o SINASC, é emitido obrigatoriamente pelo hospital onde ocorreu o parto, evitando, assim, uma grande parte de subregistros nas estatísticas de nascidos vivos do registro civil (SZWARCWALD et al., 2002). 
A DN registra um conjunto de dados sobre a mãe do nascido vivo, o pré-natal, o parto e o recém-nascido. Devido ao seu importante papel como fonte de informações relevantes para a pesquisa, avaliação e gestão da saúde da puérpera e do recém-nascido, o sistema tem sido consultado cada vez mais nos trabalhos científicos.

A subnotificação de dados do SINASC refere-se à falta de preenchimento no sistema de algum campo relacionado às condições do nascimento. A cobertura incompleta de dados do SINASC refere-se às situações de nascimentos ocorridos, mas que não foram notificados ao sistema de saúde. Embora a subnotificação e a cobertura incompleta do SINASC fossem criticadas por vários artigos, seus dados vêm se qualificando e cobertura se ampliando gradualmente, possibilitando uma melhor qualidade de pesquisas científicas. De acordo com a RIPSA (2002), as estatísticas vitais do Estado de São Paulo podem ser consideradas de excelente qualidade, sendo que a cobertura do SINASC é igual ou superior a 90\%, e também, aproximadamente 90\% das DNs do estado em 2003 apresentaram informações simultâneas para os campos: índice de Apgar $^{1}$ no quinto minuto, tipo de parto, peso ao nascer (PN), duração da gestação, número de consultas pré-natais, idade, estado civil da mãe, anos de estudo da mãe e tipo de gravidez.

Na literatura médica, encontram-se frequentemente trabalhos voltados à identificação de fatores de riscos para uma determinada morbidade ou condição utilizando dados provenientes de diversos SISs. Uma ferramenta usual para a realização de tarefas desse gênero são os modelos de regressão, sendo a regressão linear e a regressão logística bastante usuais nos estudos em saúde. Neste trabalho, foram utilizados os modelos de regressão logística. A regressão logística (HOSMER; LEMESHOW, 2000) é uma ferramenta estatística amplamente utilizada em estudos epidemiológicos sendo seus parâmetros interpretados como medidas de odds ratio ${ }^{2}(O R)$. No entanto, a interpretação do $O R$ pode não ser tão sim-

\footnotetext{
${ }^{1}$ Índice de Apgar é uma medida de 0 a 10 atribuída ao recém-nascido para medir suas condições de nascimento e a sua vitalidade. O cálculo do índice se baseia nos fatores como frequência cardíaca, respiração, cor e choro ao nascer. Quanto mais alto o valor desse índice, melhor a vitalidade do recémnascido (APGAR, 1953).

${ }^{2}$ Odds ratio é uma medida de associação entre os fatores de risco e o evento de interesse. Ela é definida como o odds para a doença entre os indivíduos expostos dividida pelo odds para a doença entre os indivíduos não-expostos. Por sua vez, um odds é definido como a probabilidade de um evento ocorrer dividida pela probabilidade deste mesmo evento não ocorrer.
} 
ples quando o fator de exposição é representado por uma variável contínua. Neste caso, é prática comum a dicotomização da variável a partir de algum ponto de corte, o que facilita a interpretação dos parâmetros gerados pelo modelo.

Entretanto, muitos autores vêm criticando esta prática de dicotomizar variáveis contínuas com este propósito. São exemplos Cumsille et al. (2000), Ragland (1992) e Royston et al. (2006). Chen et al. (2007) mostraram que em estudos do tipo caso-controle nos quais a idade é uma variável com potencial efeito de confundimento, o uso da idade dicotomizada de acordo com algum ponto de corte arbitrário pode levar a estimativas viciadas do OR. Este efeito também é discutido por Moser e Coombs (2004). Austin e Brunner (2004) utilizaram o método Monte Carlo para demonstrar que o erro tipo I é inflacionado quando é testado o efeito de uma exposição representada por uma variável contínua, mas inserida no modelo dividido em categorias. Zhao e Kolonel (1992) apresentaram também um estudo sobre este efeito. Altman e Royston (2006) mencionam que os pesquisadores podem ajustar diferentes modelos modificando o ponto de corte para a variável que expressa o fator de risco, optando pelo modelo que traz uma maior medida de efeito para a exposição (geralmente, associado a um menor $p$ value resultante de um teste de associação). No entanto, estes autores condenam tal prática, dado que é possível encontrar, desta maneira, uma associação espúria entre a exposição e o evento de interesse.

\subsection{JUSTIFICATIVA}

No mundo todo, a cada ano, cerca de 7,1 milhões de crianças perdem suas vidas antes de completar um ano de idade. Entre todas essas mortes neonatais, $98 \%$ delas ocorrem em países em desenvolvimento, como o Brasil. O baixo peso ao nascer (BPN), ou seja, quando a criança nasce com menos de 2.500 g, é o fator responsável por 40 a $70 \%$ das mortes neonatais (WORLD HEALTH ORGANIZATION - WHO, 2001). Além de ser relacionado com a morbi-mortalidade neonatal, o BPN é responsável pelo comprometimento no desenvolvimento cognitivo e pela ocorrência de doenças crônicas como hipertensão arterial, 
isquemia, doenças cardíacas, diabetes, osteoartrite entre outras, na vida adulta do indivíduo (INSTITUTE OF HEALTH ECONOMICS, 2008). A OMS identifica o BPN como o fator isolado mais importante na sobrevivência infantil (WORLD HEALTH ORGANIZATION - WHO, 1980). Por isso, o BPN tem sido utilizado como forte indicador das condições de saúde da população, por ser o determinante mais importante das chances do recém-nascido sobreviver e apresentar crescimento e desenvolvimento sa-tisfatórios (MURATA et al., 1998). Estudos relacionados aos fatores de risco para BPN são importantes no controle da morbi-mortalidade neonatal e infantil. Acredita-se que os modelos estatísticos aqui propostos serão capazes de oferecer novos entendimentos nas análises de dados de pesquisas direcionadas a esta questão.

Em muitos casos clínicos, a presença de uma doença ou uma anomalia é diagnosticada quando a variável em questão estiver contida em um determinado intervalo contínuo de valores propostos na literatura médica. Por exemplo, a OMS (1995) sugeriu que adultos com Índice de Massa Corporal (IMC) acima de $25 \mathrm{~kg} / \mathrm{m}^{2}$ podem ser considerados sobrepesos; um evento de BPN acontece quando um bebê nasce com menos de $2.500 \mathrm{~g}$. Na estimativa de risco de ocorrência desses eventos, o método tradicional de análise de regressão logística consiste em transformar essas variáveis respostas contínuas em variáveis dicotômicas, ignorando a magnitude da medida dessa variável dependente. Além disso, a dicotomização não pode ser influciada por variáveis relacionadas à determinação do ponto de corte da variável resposta, ou seja, quando, por exemplo, a etnia ou a faixa etária influencia na definição de diferentes limites entre o BPN e peso normal, essa mudança flexível de intervalo não é corrigida facilmente pelo método da dicotomização. Em resumo, a simples categorização da variável em 0 ou 1 pode trazer várias desvantagens: 1) perda de informação e a sua consequente redução do poder na identificação da relação entre as variáveis independentes e a variável resposta; 2) um fator pode ser classificado como associado à variável resposta na sua forma contínua a um nível de significância pré-estabelecido e não é associado a ela na análise de sua forma dicotômica, introduzindo assim, falsos positivos; 3) maior chance de classificação incorreta relacionada a erros de 
medição; 4) a escolha do ponto de corte pode introduzir viéses (bias), quando por exemplo, vários valores da amostra são próximos ao ponto de corte; 5) o modelo binário é sempre mais subjetivo por dicotomizar medidas contínuas (SUISSA; BLAIS, 1995; SUISSA, 1991; ALTMAN; ROYSTON, 2006).

Além desses problemas apresentados pelo método usual de estimativa de riscos, a análise com resposta contínua apresenta duas vantagens em relação à análise tradicional, segundo resultados de simulações realizadas por Suissa (1991) e Suissa e Blais (1995): 1) o método com respostas contínuas baseado no modelo Gaussiano ou no modelo Log-normal é mais eficiente que o método com resposta binária. Isto é, a variância dos estimadores obtida a partir dos modelos contínuos é menor do que aquela obtida pelo método usual, permitindo uma maior acurácia na estimativa com métodos contínuos; 2) o modelo contínuo evita os problemas de separação (ver, por exemplo, ALBERT; ANDERSON, 1984; LESAFFRE; ALBERT, 1989) que frequentemente ocorrem nos modelos binários, prejudicando a estimação de parâmetros pelo método da máxima verossimilhança (MV).

Uma aplicação do modelo de regressão logística com resposta contínua foi apresentada por Araújo (2002), onde foi considerada a previsão do risco da concentração do poluente $\mathrm{NO}_{2}$ ser maior que um valor de corte estabelecido por legislação. Variáveis climáticas e temporais foram consideradas como preditoras.

\subsection{TRABALHOS RELACIONADOS}

Na saúde coletiva foram encontrados vários artigos publicados relacionados à análises de dados do SINASC por modelos de regressão. Por exemplo, Giglio et al. (2005) basearam-se nos dados do SINASC e SIM para analisar o PN de recém-nascidos no ano 2000 em Goiânia (GO), e para identificar fatores de risco associados ao BPN. O cálculo do $O R$ como aproximação do risco relativo $(R R)^{1}$ e a regressão linear foram utilizados no estudo dos fatores de risco para $\mathrm{BPN}$.

\footnotetext{
${ }^{1}$ Segundo Pagano e Gauvreau (2006), somente em doenças raras, ou seja, doenças com baixa prevalência, o $R R$ pode ser aproximado pela $O R$.
} 
Com o objetivo de descrever o perfil das mães e recém-nascidos de uma determinada área no município de Campinas (SP), Carniel et al. (2003) analisaram os fatores de risco para BPN utilizando a regressão logística. Costa et al. (1998) identificaram fatores associados ao BPN, mediante os dados do SINASC referentes aos nascidos vivos entre janeiro e julho de 1992 em alguns municípios do Estado de São Paulo. O objetivo do trabalho de Gama et al. (2004) foi identificar o perfil das gestantes adolescentes que sofreram um número insuficiente de consultas pré-natais, considerando várias variáveis sócio-demográficas, comportamentais e biológicas. Outro trabalho teve seu enfoque na investigação de fatores de risco para mortalidade neonatal e pós-neonatal, a partir de dados do SIM e SINASC sobre nascidos vivos no ano de 1992 no município de Goiânia (NETO; BARROS, 2000). A regressão logística foi utilizada para análises multivariadas nesses estudos.

Aquino-Cunha et al. (2002) e Gama et al. (2001) conduziram trabalhos semelhantes, voltados à relação entre a gravidez na adolescência e o BPN. No trabalho de Gama et al. (2001), através da regressão logística múltipla, foi possível concluir que mães adolescentes, ausência de consultas de pré-natal e idade gestacional menor que 37 semanas são os principais fatores que se associam a BPN de uma criança. Para explicar a associação entre o BPN e mães adolescentes, Roth et al. (1998) encontram alguns fatores de natureza biológica, como imaturidade do sistema reprodutivo, ganho de peso inadequado durante a gestação e fatores socioculturais, como pobreza e marginalidade social, combinados ao estilo de vida adotado pelas adolescentes. Além disso, "a falta de cuidados pré-natais das adolescentes, associada a pobreza e níveis baixos de instrução, tem mostrado papel preponderante na cadeia causal de recém nascidos de baixo peso", conforme Gama et al. (2001). Para Aquino-Cunha et al. (2002), além da gravidez na adolescência $(O R=2,99$; com intervalo de confiança de $95 \%$ de 1,47-6,07), os outros fatores de risco para BPN são: presença de abortos anteriores $(O R=2,78 ; 1,23-6,30)$ e da doença hipertensiva específica da gravidez $(O R=5,16 ; 1,65-16,12)$. Um outro fator que contribui na associação entre mãe adolescente e BPN é relacionado à nutrição. Segundo Eisenstein et al. (2000), a 
gestação e o crescimento fetal são alterados na adolescência, por causa de maiores riscos de desnutrição, anemia, deficiências vitamínicas, retardo do crescimento intra-uterino, uso de drogas e infecções, resultando assim em maior grau de prematuridade, BPN e desnutrição pós-natal.

Em um estudo de coorte considerando 97 gestantes adolescentes, evidenciou-se que o estado nutricional pregresso, avaliado pela altura pré-gestacional, e o estado nutricional imediato, avaliado pelo ganho de peso gestacional, influenciam o peso do recém-nascido de gestantes adolescentes (GUERRA et al., 2007). Silva (2006) conduziu um estudo com o objetivo de identificar fatores de risco de mortalidade neonatal utilizando modelos da análise de regressão logística múltipla em um estudo de caso-controle baseado em dados de nascimentos ocorridos entre 2001 e 2002 no município de Campinas. Os dados dos 117 casos (óbito dentre os 28 dias de vida) foram obtidos pelo banco de dados do SIM e os 234 controles foram escolhidos aleatoriamente do SINASC. As variáveis relacionadas a atenção à saúde, condições socioeconômicas e morbidade materna foram consideradas no estudo. Várias condições foram identificadas como fatores de risco.

Em um estudo sobre a associação entre tipo de parto e o índice do Apgar no quinto minuto, Kilsztanj et al. (2007) utilizaram a análise de regressão logística simples e múltipla. Em ambos os métodos, as variáveis PN, duração da gestação, número de consultas pré-natais, idade, estado civil e anos de estudo da mãe resultaram ser todos relacionados à vitalidade do recém-nascido (avaliada pelo índice do Apgar). Na regressão logística simples, o parto cesáreo apresentou $O R$ de 0,89 para baixa vitalidade do recém-nascido, ou seja, esse tipo de parto pode proteger o baixo índice do Apgar ao quinto minuto. Entretanto, na regressão logística, onde várias variáveis foram ajustadas, o parto cesáreo registrou $O R$ de 1,045 para baixa vitalidade. Consequentemente, o tipo de parto deixou de ter uma associação significante com a baixa vitalidade do recém-nascido.

Para investigar os fatores associados à prematuridade no Estado de Santa Catarina, foi realizado um estudo transversal, com base nos dados do SINASC. Ao aplicar o modelo de regressão logística múltipla, as seguintes variáveis foram encontradas como fatores de 
risco para a prematuridade: mãe com mais de 40 ou menos de 20 anos, parto cesariano, baixa escolaridade e consultas de pré-natal insuficientes (CASCAES et al., 2008).

Percebe-se que a maioria dos trabalhos aqui citados utilizou a regressão logística como a ferramenta fundamental ou auxiliar na análise estatística. Todos esses trabalhos anteriormente citados escolheram PN para a variável resposta binária $Y_{i}$ na condução da regressão logística $(i=1, \ldots, n$,sendo $n$ o tamanho amostral). Valores 0 (para pesos maior ou igual a $2.500 \mathrm{~g}$ ) e 1 (para bebês que nascem com menos de $2.500 \mathrm{~g}$ ) foram atribuídos para essa variável. Com o modelo logístico usual, é possível obter uma boa estimativa da esperança $E(Y \mid X=x)$ para a variável dependente $Y$, dada a exposição ou não exposição ao fator $X$ (este fator pode ser, por exemplo, a escolaridade ou a idade materna). Porém, segundo um estudo da regressão logística com resposta contínua e uma simulação realizada por Suissa e Blais (1995), os estimadores de MV dos parâmetros com resposta contínua são de $25 \%$ a $85 \%$ mais eficientes que os estimadores de MV dos parâmetros do modelo logístico tradicional. Em outras palavras, quando considerar a variável PN uma variável aleatória contínua e estimar a probabilidade de que a resposta seja superior a $2.500 \mathrm{~g}$ (ou inferior a $2.500 \mathrm{~g}$ ), pode obter respostas mais corretamente ajustadas. Nesse caso, considera-se que $c=2.500 \mathrm{~g}$ seja o valor de corte com base na literatura médica, ver, por exemplo, WHO (1950). O risco $\pi_{i}$, que é a probabilidade de que a resposta seja inferior ao valor de corte, é o parâmetro de interesse do estudo. Dessa forma, é permitido utilizar os dados sobre PN diretamente do banco de dados do SINASC como uma variável contínua, sem a conversão desses valores em 0 ou 1. 


\section{OBJETIVO}

\subsection{OBJETIVO PRINCIPAL}

O objetivo do presente trabalho é estudar o desempenho da regressão binária com resposta contínua, introduzida por Suissa (1991), na análise de dados do SINASC ao investigar os fatores de risco associados ao BPN. O modelo apresentado pode ser útil também na análise de outros bancos de dados, nos estudos que objetivam avaliar a associação entre um conjunto de variáveis (contínuas ou categóricas) independentes e uma variável resposta contínua, onde um ponto de corte é especificado previamente. Nesta situação, é avaliada a probabilidade condicional de se observar um valor desta resposta acima (ou abaixo) deste ponto de corte, condicionada à observação de um conjunto de variáveis independentes. Esta situação é comum ainda em estudos clínicos, onde se pretende avaliar fatores associados a dados laboratoriais expressos em valores contínuos (por exemplo, em uma situação onde o objetivo é avaliar os fatores de risco associados à hipercolesterolemia, ou seja, observação de valores do colesterol total acima de um ponto de corte estabelecido clinicamente).

\subsection{OBJETIVOS SECUNDÁRIOS}

a) Analisar o modelo de regressão binária com resposta contínua para a análise dos dados do SINASC.

b) Comparar o desempenho da regressão binária com resposta contínua na análise dos dados do SINASC, com o desempenho dos modelos usuais de regressão, ou seja, com resposta dicotomizada. 


\section{METODOLOGIA}

Neste capítulo, são apresentados vários métodos estatísticos utilizados na análise de dados deste estudo, bem como os principais fatores de risco para BPN já identificados segundo a literatura, apresentados na Sub-seção 3.1. Baseado nas informações sobre esses fatores de risco, foram selecionados, na análise de dados, os critérios de inclusão e exclusão. Além disso, essas informações serviram de referência para a comparação entre os resultados obtidos nas análises estatísticas do estudo e os fatores de risco identificados na literatura. Na Sub-seção 3.2, o banco de dados utilizado na análise é apresentado. Na Subseção 3.3, é apresentada a aprovação deste estudo pelo Comitê de Ética em Pesquisa. Na Sub-seção 3.4, a regressão logística, metodologia estatística usual desse tipo de análise, é descrita. Na Sub-seção 3.5, a regressão binária com variável resposta contínua, metodologia proposta neste estudo, é apresentada. Na Sub-seção 3.6, são apresentadas noções gerais sobre a curva ROC, esta que foi utilizada no teste de avaliação dos resultados obtidos para comparar os dois métodos estatísticos implementados. Nas Sub-seções 3.7 e 3.8 são introduzidos a implementação computacional e o método da Estimativa por MV.

\subsection{PRINCIPAIS FATORES DE RISCO PARA BPN IDENTIFICADOS NA LITERA- TURA}

Para obter uma visão geral sobre os fatores de risco já identificados que contribuem para o BPN de crianças, vários estudos foram revisados. Pode-se citar no presente estudo uma revisão sistemática elaborada pelo Institute of Health Economics (2008), devido a sua abrangência no assunto. De acordo com o instituto, há vários possíveis fatores associados ao BPN e parto prematuro (duração de gestação até 37 semanas), entre eles:

- fatores demográficos da mãe: idade gestacional materna extrema, primiparidade, grande número de partos sofridos por mãe, intervalo inter-gravidez extremo, mães solteiras e gravidez não desejada; 
- características antropométricas da mãe: estatura materna pequena, baixo peso prégestacional, alto índice de massa corporal pré-gestacional e ganho do peso gestacional inadequado;

- fatores intergeracionais, paternos e fetais: fatores genéticos, algumas síndromes, idade gestacional paterna avançada e histórico de BPN na mãe;

- fatores médicos da mãe: algumas doenças maternas como hipertensão, diabetes, infecções, asma, insuficiência renal, anemia falciforme, entre outras, histórico de aborto induzido, anormalidades estruturais no útero, anormalidades na placenta que causam redução do seu fluxo sanguíneo e ingestão de alguns tipos de fármacos;

- gravidez múltipla;

- fatores psico-sociais e socio-econômicos: raça, estresse agudo ou crônico, classe social desfavorecida e ambiente de trabalho de risco;

- fatores de estilos de vida: uso de cigarro, álcool, cafeína e drogas;

- fatores ambientais: exposição ao ar poluído, água contaminada, pesticidas e campos eletromagnéticos;

- fatores ocupacionais: trabalhos que exijam uma demanda física da mãe, bem como um longo período de permanência em pé, além de trabalhos associados ao estresse ou exposição a alguns fatores prejudiciais ao feto, presença de violência e abusos durante a gravidez;

- fatores nutricionais: nutrição fetal inadequada;

- infecções: vaginose bacteriana, tricomoníase, gonorréia, sífilis, malária, Síndrome da Imunodeficiência Adquirida, infecção no trato urinário, doenças periodontais;

- cuidados do pré-natal: consultas regulares pré-natais podem detectar algumas anomalias que resultam no BPN ou em nascimentos prematuros.

Com essas informações e o banco de dados descrito abaixo, foi possível incluir ou excluir as variáveis que participarão na análise do projeto. 


\subsection{BANCO DE DADOS}

O banco de dados do SINASC disponível em CD-ROM (distribuído pela Secretaria de Vigilância em Saúde do MS) foi utilizado para esta análise. O Município de Ribeirão Preto (SP) foi escolhido para a realização desta pesquisa. Os dados mais recentes disponibilizados, ou seja, os dados do ano de 2005, foram utilizados.

Os arquivos do banco de dados do SINASC no CD-ROM são armazenados em formato DBF. Para visualizar os registros, foi necessário utilizar o programa TABWIN (disponível no site do DATASUS) para descompactar os arquivos para o formato DBC. Nesse banco de dados, as seguintes variáveis são encontradas:

- Número de identificação da DN: uma sequência única de 8 dígitos para cada DN;

- Local de ocorrência do nascimento, classificado em: hospital, outro estabelecimento de saúde, domicílio, outros ou ignorado;

- Código de estabelecimento: código de 9 dígitos para identificar o estabelecimento do nascimento;

- Código do bairro do nascimento: código de 3 dígitos para identificar o bairro onde ocorreu o nascimento;

- Município de ocorrência: código de identificação de 7 dígitos para representar o município onde o parto ocorreu;

- $\quad$ Idade materna: idade da mãe em anos;

- $\quad$ Estado civil da mãe, categorizado em: solteira, viúva, separada judicialmente ou divorciada, casada, união consensual ou ignorado;

- $\quad$ Escolaridade da mãe, categorizada em: nenhuma, 1 a 3 anos, 4 a 7 anos, 8 a 11 anos e mais que 12 anos de estudo ou ignorado;

- $\quad$ Ocupação da mãe: código identificando a ocupação da mãe, conforme a Classificação Brasileira de Ocupações;

- $\quad$ Número de filhos vivos: quantidade de filhos vivos que a mãe possui;

- $\quad$ Número de filhos mortos: quantidade de filhos mortos da mãe; 
- Código do bairro de residência: código de identificação de 3 dígitos para representar o bairro onde a mãe reside;

- Município de residência: código de identificação de 7 dígitos para representar o município de residência da mãe;

- Duração da gestação em semanas, classificada em: menos de 22 semanas, 22 a 27 semanas, 28 a 31 semanas, 32 a 36 semanas, 37 a 41 semanas, 42 semanas e mais ou ignorado;

- $\quad$ Tipo de gravidez, categorizado em: única, dupla, tripla e mais ou ignorado;

- $\quad$ Tipo de parto, que pode ser: vaginal ou cesáreo;

- Número de consultas de pré-natal, classificado em: nenhuma, 1 a 3, 4 a 6, 7 e mais consultas ou ignorado;

- Data de nascimento da criança;

- Sexo do recém-nascido, com categorias: masculino, feminino ou ignorado;

- $\quad$ Índice de Apgar no primeiro minuto, com: valor inteiro de 0 a 10;

- $\quad$ Índice de Apgar no quinto minuto, com: valor inteiro de 0 a 10;

- $\quad$ Etnia ou cor do nascido, que assume as categorias: branca, negra, amarela, parda ou indígena;

- $\quad$ PN do bebê em gramas;

- Variável indicadora da presença ou não da anomalia: 1 indica sim e 2 indica não;

- Código de malformação congênita ou anomalia cronossômica de 4 dígitos, de acordo com a CID10;

- Código da Unidade Federativa que informou os dados, conforme IBGE.

As seguintes variáveis contidas no banco de dados original do SINASC foram desconsideradas: número da DN, código de estabelecimento, código bairro nascimento, município de ocorrência do parto, código bairro residência, município de residência, data de nascimento e código da Unidade Federativa. A variável "etnia" é estudada no projeto pois vários autores, bem como o Institute of Health Economics (2008), queixaram-se de uma necessidade de estudos mais profundos para investigar o impacto desta no risco do BPN. 
Segundo a mesma fonte bibliográfica, a variável "sexo", apresenta geralmente um comportamento constante: os recém-nascidos de sexo masculino possuem, em geral, maior PN em comparação com os bebês de sexo feminino. Porém, não se pode confirmar se essa diferença no peso é significante ou não para classificar se um indivíduo nasceu com baixo peso ou peso normal. Por isso, também foi incluída a variável "sexo" para a análise de dados. A presença de uma anomalia congênita influencia muito o PN da criança, sempre contribuindo em um BPN extremo, assim como a duração da gestação extremamente curta e as gravidezes duplas, triplas ou múltiplas. Registros de anomalia congênita, gravidezes múltiplas e gestações com duração abaixo de 32 semanas, que são fatores de risco para BPN extremo reconhecidos na literatura, foram excluídos da análise. O índice de Apgar é uma medida de 0 a 10 atribuída ao recém-nascido para medir suas condições de nascimento (ver na Seção 1 explicações mais detalhadas). Essa escala é diretamente relacionada ao PN de uma criança. Porém, esse índice foi excluído da análise de dados pois não é um fator que influencia a variável resposta, mas uma das consequências (respostas) de outros fatores de risco.

As variáveis restantes foram consideradas para a análise na identificação de fatores de risco para BPN. Para a variável "duração da gestação", segundo Neme (1994), a ocorrência do parto de 22 a 37 semanas de gestação é considerado parto pré-maturo. Assim, é obstetricamente correto classificar a duração da gestação levando em consideração o limiar da separação de 37 semanas. Uma dificuldade de análise foi encontrada ao estudar o comportamento da idade materna em relação ao risco de filhos nascerem com baixo peso. Segundo a literatura estudada, o risco do BPN aumenta para mães adolescentes e mães com idade avançada. Para mães entre 20 e 30 anos, esse risco é reduzido. Dessa forma, ao conservar sua forma natural de variável contínua, sendo a regressão logística uma ferramenta utilizada para análise de dados somente com comportamentos ascendentes ou descendentes, a análise com a variável idade não trará resultados confiáveis. Esse comportamento da curva risco do BPN versus idade é ilustrado na Figura 1, onde o percentual de BPN nas diferentes faixas etárias não apresenta um comportamento monótono, como 


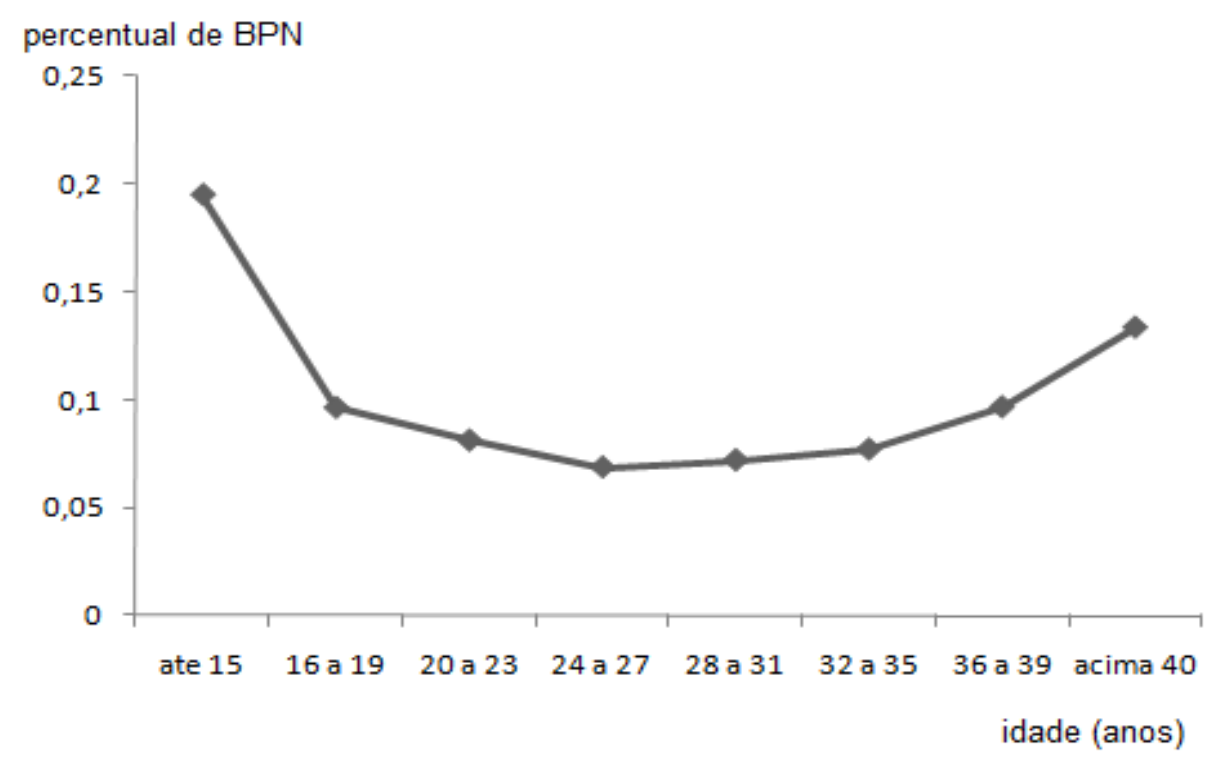

Figura 1: Percentual de BPN de mães nas diferentes faixas etárias, SINASC de Ribeirão Preto em 2005

seria esperado para a aplicação de uma regressão logística. Também foi elaborado um gráfico de dispersão entre idade materna e PN. Não foi encontrada uma correlação linear entre as duas variáveis. Para atenuar o problema, a idade materna foi classificada em diferentes faixas etárias, separando-a em categorias de mães adolescentes muito jovens (de 10 a 15 anos), mães adolescentes (16 a 19 anos), dentro da faixa etária ideal para parturições (20 a 29 anos), com idades entre 30 e 39 anos e com idades avançadas (mais que 40 anos).

Além dessas alterações, a ocupação da mãe apresenta muitas variações e subregistros. Devido à dificuldade de análise, ela não foi incluída no estudo. Na variável raça, ao se elaborar a tabela de frequencia, indícios de problemas de separação foram observados. Além disso, algumas categorias possuem um número extremamente pequeno de registros (nas categorias indígena e amarela, por exemplo), comprometendo, dessa forma, o poder do teste. Os problemas de separação são aqueles casos nos quais uma determinada categoria se classifica totalmente em um evento de interesse (BPN, por exemplo) e, consequentemente, não apresenta nenhum registro no evento complementar (peso normal, por exemplo). Nesses problemas, ocorre o impedimento da obtenção do $O R$ na referente 
categoria devido à formulação matemática do cálculo do $O R$. A solução usual para esses problemas é a junção de duas ou mais categorias dessa variável. Dessa forma, a variável raça é classificada em branca, negra e outras. O mesmo ocorreu com a variável situação conjugal da mãe. Em vários estudos preliminares, não foram encontradas evidências entre a quantidade de filhos vivos ou mortos da mulher e o BPN. Para utilizar essas informações, a variável "é ou não primípara" foi determinada. Nesta variável, se ambas as variáveis "número de filhos vivos" e "número de filhos mortos" apresentarem valor 0, é considerado que a mãe é primípara. Caso contrário, o referido recém-nascido não seria o primeiro parto da mãe. Por fim, visando um melhor ajuste ao utilizar o modelo da regressão binária com resposta contínua, adotou-se o PN em quilogramas.

Dessa forma, as seguintes variáveis com as suas respectivas categorias utilizadas na análise de dados do SINASC de Ribeirão Preto são:

- Idade materna, categorizada em: até 15 anos, 16 a 19 anos, 20 a 29 anos, 30 a 39 anos e 40 anos ou mais;

- $\quad$ Situação conjugal da mãe, que pode ser: solteira, viúva ou separada, casada e união consensual;

- $\quad$ Escolaridade da mãe, categorizada em: nenhuma, 1 a 3 anos, 4 a 7 anos, 8 a 11 anos e mais que 12 anos de estudo;

- $\quad$ Duração da gestação em semanas, classificada em: 32 a 36 semanas e 37 semanas ou mais (De acordo com Arias e Tomich (1982), RN com menos de 37 semanas completas de gestação são classificados usualmente como pré-termos.);

- $\quad$ Tipo de parto, que pode ser: vaginal ou cesáreo;

- $\quad$ Número de consultas pré-natais, classificado em: nenhuma, 1 a 3, de 4 a 6 e 7 ou mais consultas;

- $\quad$ Etnia ou cor do nascido, que assume as categorias: branca, negra e outras;

- $\quad$ Sexo do nascido vivo: masculino ou feminino;

- $\quad$ Ser ou não primípara; 
- $\quad$ PN do bebê em quilogramas;

Como foi citado anteriormente, o critério de exclusão dos registros são: os nascidos vivos com algumas variáveis incluídas incompletas (sub-registro de algumas informações no sistema); os nascidos vivos portadores de alguma anomalia congênita, os registros de gravidez múltipla (dupla ou mais); e os recém-nascidos com idade gestacional de até 31 semanas.

\subsection{QUESTÕES ÉTICAS}

O presente projeto foi encaminhado ao Comitê de Ética em Pesquisa do Hospital das Clínicas de Ribeirão Preto e da Faculdade de Medicina de Ribeirão Preto, sendo aprovado pelo mesmo em julho de 2009. O Ofício da aprovação do projeto encontra-se no Anexo A deste trabalho.

\subsection{REGRESSÃO LOGÍSTICA USUAL}

O objetivo da regressão logística usual é descrever as relações entre uma variável dependente binária $(Y)$ e um conjunto de $k$ va-riáveis dependentes, denotado pelo vetor $\mathbf{X}=\left(X_{1}, X_{2}, \ldots, X_{k}\right)^{\prime}$. No contexto do presente projeto, o PN é considerado a variável

dependente $Y$ e as variáveis independentes apresentadas na subseção anterior formam o vetor $\mathbf{X}$.

Como a variável dependente $Y$ é binária, ou seja, recebe valores 0 ou 1, ela pode ser apresentada da seguinte forma, quando esta denota se um indivíduo nasceu com baixo peso $(<2.500 \mathrm{~g})$ ou não:

$$
Y\left\{\begin{array}{l}
0 \text { se PN for maior ou igual a } 2.500 \mathrm{~g} . \\
1 \text { se BPN, isto é, PN menor que } 2.500 \mathrm{~g} .
\end{array}\right.
$$


Dessa forma, $Y$ segue uma distribuição de Bernoulli com probabilidade de sucesso dada por $\pi$. Ou seja, se $Y \sim \operatorname{Bernoulli}(\pi)$, resulta em:

$$
\left.\begin{array}{l}
P(Y=1)=\pi \\
P(Y=0)=1-\pi
\end{array}\right\} \quad P(Y=y)=\pi^{y}(1-\pi)^{1-y} \text { se } y=0,1
$$

onde $y$ é uma observação amostral de $Y$. Tem-se que $E(Y)=\pi$ e $\operatorname{Var}(Y)=\pi(1-\pi)$.

O modelo de regressão tem o objetivo de estimar $E(Y \mid X=x)$, se consideramos uma única variável independente. Se $Y \sim \operatorname{Bernoulli}[\pi(x)]$, a esperança $E(Y \mid X=x)$ é dada por:

$$
\begin{aligned}
E(Y \mid X=x) & =1 \times P(Y=1 \mid X=x)+0 \times P(Y=0 \mid X=x) \\
& =P(Y=1 \mid X=x)=\pi(x),
\end{aligned}
$$

tal que $0<\pi(x)<1$ e $x$ é uma observação amostral de $X$.

O modelo de regressão linear usual dado por $E(Y \mid X=x)=\beta_{0}+\beta_{1} x$ não é adequado nesta situação, pois nada nos garante que $0<\beta_{0}+\beta_{1} x<1$. Para isso, utiliza-se o modelo de regressão logística, que é dado por:

$$
E(Y \mid X=x)=\pi(x)=\frac{e^{\beta_{0}+\beta_{1} x}}{1+e^{\beta_{0}+\beta_{1} x}}=\frac{e^{g(x)}}{1+e^{g(x)}},
$$

na qual $g(x)=\beta_{0}+\beta_{1} x$. Dessa forma, tem-se:

$$
1-\pi(x)=1-\frac{e^{g(x)}}{1+e^{g(x)}}=\frac{1+e^{g(x)}-e^{g(x)}}{1+e^{g(x)}}=\frac{1}{1+e^{g(x)}}
$$

e:

$$
\frac{\pi(x)}{1-\pi(x)}=\frac{e^{g(x)}}{1+e^{g(x)}} 1+e^{g(x)}=e^{g(x)}
$$

e consequentemente:

$$
g(x)=\ln \left[\frac{\pi(x)}{1-\pi(x)}\right]
$$


Pode-se notar também que:

$$
\pi(x)=\frac{e^{g(x)}}{1+e^{g(x)}}=\left[\frac{1+e^{g(x)}}{e^{g(x)}}\right]^{-1}=\left[1+\frac{1}{e^{g(x)}}\right]^{-1}=\frac{1}{1+e^{-g(x)}} .
$$

Deve-se encontrar, no próximo passo, estimadores para $\beta_{0}$ e $\beta_{1}$. O método mais utilizado para a obtenção de estimativas para $\beta_{0}$ e $\beta_{1}$ nos modelos de regressão logística é o da máxima verossimilhança (MV).

Seja uma amostra tamanho $n$. Para cada indivíduo, $i=1, \ldots, n$, tem-se:

$$
\pi\left(x_{i}\right)=\frac{e^{\beta_{0}+\beta_{1} x_{i}}}{1+e^{\beta_{0}+\beta_{1} x_{i}}} .
$$

Considerando $Y_{i} \mid X_{i}=x_{i} \sim \operatorname{Bernoulli}\left[\pi\left(x_{i}\right)\right]$, tem-se:

$$
P\left(Y_{i}=y_{i} \mid X_{i}=x_{i}\right)=\left[\pi\left(x_{i}\right)\right]^{y_{i}}\left[1-\pi\left(x_{i}\right)\right]^{1-y_{i}},
$$

para $i=1, \ldots, n$. O método da MV diz que os estimadores $\widehat{\beta}_{0}$ e $\widehat{\beta}_{1}$ para $\beta_{0}$ e $\beta_{1}$ são escolhidos como aqueles que maximizam a função:

$$
L\left(\beta_{0}, \beta_{1}\right)=\prod_{i=1}^{n} P\left(Y_{i}=y_{i} \mid X_{i}=x_{i}\right)=\prod_{i=1}^{n}\left\{\left[\pi\left(x_{i}\right)\right]^{y_{i}}\left[1-\pi\left(x_{i}\right)\right]^{1-y_{i}}\right\},
$$

considerando $Y_{1}, Y_{2}, \ldots, Y_{n}$ independentes. A função $L\left(\beta_{0}, \beta_{1}\right)$ é denominada função de verossimilhança. Para encontrar $\widehat{\beta}_{0}$ e $\widehat{\beta}_{1}$ que maximizam $L\left(\beta_{0}, \beta_{1}\right)$, deriva-se $L\left(\beta_{0}, \beta_{1}\right)$ em relação a $\beta_{0}$ e a $\beta_{1}$ igualando os resultados a zero. Para facilitar os cálculos, utiliza-se a propriedade de que os valores de $\beta_{0}$ e $\beta_{1}$ que maximizam $L\left(\beta_{0}, \beta_{1}\right)$ também maximizam o logaritmo de $L\left(\beta_{0}, \beta_{1}\right)$, que é dado por:

$$
\ln L\left(\beta_{0}, \beta_{1}\right)=\sum_{i=1}^{n}\left\{y_{i} \ln \left[\pi\left(x_{i}\right)\right]+\left(1-y_{i}\right) \ln \left[1-\pi\left(x_{i}\right)\right]\right\}
$$

Para isto, alguns resultados são úteis: 
- $\ln \pi\left(x_{i}\right)=\ln \left(\frac{e^{\beta_{0}+\beta_{1} x_{i}}}{1+e^{\beta_{0}+\beta_{1} x_{i}}}\right)=\beta_{0}+\beta_{1} x_{i}-\ln \left(1+e^{\beta_{0}+\beta_{1} x_{i}}\right)$

- $\ln \left[1-\pi\left(x_{i}\right)\right]=\ln \left(\frac{1}{1+e^{\beta_{0}+\beta_{1} x_{i}}}\right)=-\ln \left(1+e^{\beta_{0}+\beta_{1} x_{i}}\right)$;

- $\frac{\partial \ln \pi\left(x_{i}\right)}{\partial \beta_{0}}=1-\frac{e^{g(x)}}{1+e^{g(x)}}=1-\pi\left(x_{i}\right)$;

- $\frac{\partial \ln \pi\left(x_{i}\right)}{\partial \beta_{1}}=x_{i}-\frac{x_{i} e^{g(x)}}{1+e^{g(x)}}=x_{i}\left[1-\pi\left(x_{i}\right)\right]$;

- $\frac{\partial \ln \left[1-\pi\left(x_{i}\right)\right]}{\partial \beta_{0}}=-\frac{e^{g(x)}}{1+e^{g(x)}}=-\pi\left(x_{i}\right) \quad \mathrm{e}$

- $\frac{\partial \ln \left[1-\pi\left(x_{i}\right)\right]}{\partial \beta_{1}}=-x_{i} \frac{e^{g(x)}}{1+e^{g(x)}}=-x_{i} \pi\left(x_{i}\right)$.

A partir destes resultados, tem-se:

$$
\begin{aligned}
\frac{\partial \ln L\left(\beta_{0}, \beta_{1}\right)}{\partial \beta_{0}} & =\sum_{i=1}^{n}\left\{y_{i}\left[1-\pi\left(x_{i}\right)\right]+\left(1-y_{i}\right)\left[-\pi\left(x_{i}\right)\right]\right\} \\
& =\sum_{i=1}^{n}\left[y_{i}-y_{i} \pi\left(x_{i}\right)-\pi\left(x_{i}\right)+y_{i} \pi\left(x_{i}\right)\right] \\
& =\sum_{i=1}^{n}\left[y_{i}-\pi\left(x_{i}\right)\right]
\end{aligned}
$$

e:

$$
\frac{\partial \ln L\left(\beta_{0}, \beta_{1}\right)}{\partial \beta_{1}}=\sum_{i=1}^{n} x_{i}\left[y_{i}-\pi\left(x_{i}\right)\right] .
$$

Os estimadores de MV $\widehat{\beta}_{0}$ e $\widehat{\beta}_{1}$ são então dados pelos valores de $\beta_{0}$ e $\beta_{1}$ que satisfazem às equações:

$$
\sum_{i=1}^{n}\left[y_{i}-\pi\left(x_{i}\right)\right]=0
$$

e:

$$
\sum_{i=1}^{n} x_{i}\left[y_{i}-\pi\left(x_{i}\right)\right]=0 .
$$

Observando estas equações, nota-se que não é possível encontrar fórmulas explícitas para $\widehat{\beta}_{0}$ e $\widehat{\beta}_{1}$. A solução é encontrada com o auxílio de ferramentas de cálculo numérico baseadas em métodos iterativos, como o método de Newton-Raphson. 


\subsubsection{O modelo múltiplo}

Seja um vetor de $k$ variáveis independentes com observações denotadas pelo vetor $\mathbf{x}=\left(x_{1}, x_{2}, \ldots, x_{k}\right)^{\prime}$. A probabilidade condicional de "sucesso" associada à variável $Y$ é denotada por:

$$
P(Y=1 \mid \mathbf{X}=\mathbf{x})=\pi(\mathbf{x})
$$

Considerando a relação linear:

$$
h(\mathbf{x})=\beta_{0}+\beta_{1} x_{1}+\beta_{2} x_{2}+\ldots+\beta_{k} x_{k}
$$

a probabilidade condicional $\pi(\mathbf{x})$ é escrita na forma:

$$
\pi(\mathbf{x})=\frac{e^{h(\mathbf{x})}}{1+e^{h(\mathbf{x})}}
$$

sendo $\boldsymbol{\beta}=\left(\beta_{0}, \beta_{1}, \beta_{2}, \ldots, \beta_{k},\right)^{\prime}$ o vetor de $k+1$ parâmetros do modelo. Estimadores de MV $\widehat{\beta}_{0}, \widehat{\beta}_{1}, \ldots, \widehat{\beta}_{k}$, para $\beta_{0}, \beta_{1}, \beta_{2}, \ldots, \beta_{k}$, respectivamente, são obtidos das expressões:

$$
\sum_{i=1}^{n}\left[y_{i}-\pi\left(\mathbf{x}_{i}\right)\right]=0
$$

e:

$$
\sum_{i=1}^{n} x_{i j}\left[y_{i}-\pi\left(\mathbf{x}_{i}\right)\right]=0
$$

para $j=1,2, \ldots, k$.

Novamente, a solução para estas expressões é baseada em métodos iterativos e demanda o uso de programas computacionais. 


\subsubsection{Erros padrão}

Considerando o modelo de regressão logística simples, as derivadas de segunda ordem de $\ln L\left(\beta_{0}, \beta_{1}\right)$ são dadas por:

$$
\begin{aligned}
& \frac{\partial^{2} \ln L\left(\beta_{0}, \beta_{1}\right)}{\partial \beta_{0}^{2}}=-\sum_{i=1}^{n} \pi\left(x_{i}\right)\left[1-\pi\left(x_{i}\right)\right], \\
& \frac{\partial^{2} \ln L\left(\beta_{0}, \beta_{1}\right)}{\partial \beta_{1}^{2}}=-\sum_{i=1}^{n} x_{i}^{2} \pi\left(x_{i}\right)\left[1-\pi\left(x_{i}\right)\right], \quad \mathrm{e} \\
& \frac{\partial^{2} \ln L\left(\beta_{0}, \beta_{1}\right)}{\partial \beta_{0} \beta_{1}}=-\sum_{i=1}^{n} x_{i} \pi\left(x_{i}\right)\left[1-\pi\left(x_{i}\right)\right] .
\end{aligned}
$$

Assim, a matriz de informação $\mathbf{I}\left(\beta_{0}, \beta_{1}\right)$ é dada por:

$$
\mathbf{I}\left(\beta_{0}, \beta_{1}\right)=\left[\begin{array}{cc}
\sum_{i=1}^{n} \pi\left(x_{i}\right)\left[1-\pi\left(x_{i}\right)\right] & \sum_{i=1}^{n} x_{i} \pi\left(x_{i}\right)\left[1-\pi\left(x_{i}\right)\right] \\
\sum_{i=1}^{n} x_{i} \pi\left(x_{i}\right)\left[1-\pi\left(x_{i}\right)\right] & \sum_{i=1}^{n} x_{i}^{2} \pi\left(x_{i}\right)\left[1-\pi\left(x_{i}\right)\right]
\end{array}\right]
$$

Seja $\widehat{\sigma}^{2}\left(\beta_{j}\right)$ o $j$-ésimo elemento da diagonal da matriz $\mathbf{I}^{-1}\left(\widehat{\beta}_{0}, \widehat{\beta}_{1}\right), j=0,1$. Assim, o erro padrão estimado para $\widehat{\beta}_{j}$ é dado por:

$$
\widehat{e p}\left(\widehat{\beta}_{j}\right)=\sqrt{\widehat{\sigma}^{2}\left(\beta_{j}\right)}
$$

Considerando o modelo de regressão logística múltipla com $k$ variáveis, sejam os dados amostrais representados pela matriz $\mathbf{X}$, de dimensão $n \times(k+1)$ :

$$
\mathbf{X}=\left[\begin{array}{cccc}
1 & x_{11} & \cdots & x_{1 k} \\
1 & x_{21} & \cdots & x_{2 k} \\
\vdots & \vdots & \ddots & \vdots \\
1 & x_{n 1} & \cdots & x_{n k}
\end{array}\right]
$$


Seja $\mathbf{V}$ uma matriz de dimensão $n \times n$, dada por:

$$
\mathbf{V}=\left[\begin{array}{cccc}
\pi\left(x_{1}\right)\left[1-\pi\left(x_{1}\right)\right] & 0 & \cdots & 0 \\
0 & \pi\left(x_{2}\right)\left[1-\pi\left(x_{2}\right)\right] & \cdots & 0 \\
\vdots & \vdots & \ddots & \vdots \\
0 & 0 & \cdots & \pi\left(x_{n}\right)\left[1-\pi\left(x_{n}\right)\right]
\end{array}\right]
$$

A matriz de informação $\mathbf{I}(\boldsymbol{\beta})$ é agora dada por $\mathbf{I}(\boldsymbol{\beta})=\mathbf{X}^{T} \mathbf{V X}$, sendo o erro padrão

estimado para $\widehat{\beta}_{j}(j=0,1, \ldots, k)$ dado por $\widehat{e p}\left(\widehat{\beta}_{j}\right)=\sqrt{\widehat{\sigma}^{2}\left(\beta_{j}\right)}$, no qual $\widehat{\sigma}^{2}\left(\beta_{j}\right)$ é o $j$-ésimo elemento da diagonal da matriz $\mathbf{I}^{-1}(\boldsymbol{\beta})$.

\subsubsection{Medidas de ajuste e comparação entre modelos}

Algumas medidas que indicam a qualidade do ajuste dos modelos são:

\section{1) Deviance:}

Esta estatística é utilizada na comparação de vário modelos. Ela compara $L\left(\widehat{\beta}_{0}, \widehat{\beta}_{1}\right)$, a verossimilhança baseada nos valores estimados para $\beta_{0}$ e $\beta_{1}$ utilizando o modelo referente, com a verossimilhança que seria encontrada a partir de um modelo saturado. Um modelo saturado é aquele que contém tantos parâmetros quanto observações amostrais. A deviance $D$ é dada por:

$$
D=-2 \ln \frac{\text { verossimilhança do modelo ajustado }}{\text { verossimilhança do modelo saturado }}
$$

Considerando a Equação (9), onde é definido o $\pi\left(x_{i}\right)$ na regressão logística, tem-se que $\widehat{\pi}\left(x_{i}\right)$ é estimado por:

$$
\widehat{\pi}\left(x_{i}\right)=\frac{e^{\widehat{\beta}_{0}+\widehat{\beta}_{1} x_{i}}}{1+e^{\widehat{\beta}_{0}+\widehat{\beta}_{1} x_{i}}} .
$$


Assim,

$$
\begin{aligned}
D & =-2 \ln \frac{\prod_{i=1}^{n}\left\{\left[\widehat{\pi}\left(x_{i}\right)\right]^{y_{i}}\left[1-\widehat{\pi}\left(x_{i}\right)\right]^{1-y_{i}}\right\}}{\prod_{i=1}^{n}\left\{y_{i}^{y_{i}}\left[1-y_{i}\right]^{1-y_{i}}\right\}} \\
& =-2 \ln \prod_{i=1}^{n}\left\{\left[\frac{\widehat{\pi}\left(x_{i}\right)}{y_{i}}\right]^{y_{i}}\left[\frac{1-\widehat{\pi}\left(x_{i}\right)}{1-y_{i}}\right]^{1-y_{i}}\right\} \\
& =-2 \sum_{i=1}^{n}\left[y_{i} \ln \frac{\widehat{\pi}\left(x_{i}\right)}{y_{i}}+\left(1-y_{i}\right) \ln \frac{1-\widehat{\pi}\left(x_{i}\right)}{1-y_{i}}\right] .
\end{aligned}
$$

Porém, nota-se que esta expressão pode resultar em vários problemas, dado que $y_{i}$ assume valores 0 e 1 . Assim, uma expressão plausível para $D$ é dada por:

$$
D=-2 \sum_{i=1}^{n}\left\{\ln \left[\widehat{\pi}\left(x_{i}\right)\right] I_{\{1\}}\left(y_{i}\right)+\ln \left[1-\widehat{\pi}\left(x_{i}\right)\right] I_{\{0\}}\left(y_{i}\right)\right\}
$$

na qual $I_{\{a\}}\left(y_{i}\right)$ é uma função indicadora tal que:

$$
I_{\{a\}}\left(y_{i}\right)=\left\{\begin{array}{c}
1 \text { se } y_{i}=a \\
0 \text { se } y_{i} \neq a
\end{array}\right.
$$

onde $a=0,1$. Menores valores de $\mathrm{D}$ indicam modelo com melhor ajuste.

2) Critério de informação de Akaike $(A I C)$ :

O critério de informação de Akaike (Akaike's information criterion, AIC) é dado por:

$$
A I C=D+2 k
$$

onde $D$ é a deviance e $k$ é o número de parâmetros do modelo. Considera-se que quanto menor o valor do $A I C$, melhor é o ajuste do modelo. O termo $2 k$ é uma "penalidade", ou seja, modelos com muitos parâmetros terão maior AIC (AKAIKE, 1974).

3) Critério Bayesiano de informação $(B I C)$ : 
O critério Bayesiano de informação (Bayesian information criterion, BIC) é dado por:

$$
B I C=D+k \ln (n)
$$

onde $D$ é a deviance, $k$ é o número de parâmetros do modelo e $n$ é o tamanho da amostra. Como o BIC "penaliza" a deviance também pelo tamanho da amostra, esta medida é bastante útil nas situações onde os tamanhos amostrais são relativamente grandes (SCHWARZ, 1978).

\subsubsection{Estimativa do odds ratio}

Seja $X$ uma variável binária representando um fator de risco, tal que $X=1$ denota a exposição e $X=0$ denota a não exposição ao fator de risco. Assim, da definição usual de $O R$, tem-se:

$$
O R=\frac{P(Y=1 \mid X=1) P(Y=0 \mid X=0)}{P(Y=1 \mid X=1) P(Y=1 \mid X=1)},
$$

Considerando a Tabela 1,

Tabela 1: Probabilidades condicionais $P(Y=y \mid X=x)$, onde $X$ é uma variável binária.

\begin{tabular}{llcc}
\hline & & \multicolumn{2}{c}{ Resposta } \\
& & $Y=1$ & $Y=0$ \\
\hline Fator de risco & $X=1$ & $\frac{e^{\beta_{0}+\beta_{1}}}{1+e^{\beta_{0}+\beta_{1}}}$ & $\frac{1}{1+e^{\beta_{0}+\beta_{1}}}$ \\
& $X=0$ & $\frac{e^{\beta_{0}}}{1+e^{\beta_{0}}}$ & $\frac{1}{1+e^{\beta_{0}}}$ \\
\hline
\end{tabular}

tem-se:

$$
O R=\frac{\left(\frac{e^{\beta_{0}+\beta_{1}}}{1+e^{\beta_{0}+\beta_{1}}}\right)\left(\frac{1}{1+e^{\beta_{0}}}\right)}{\left(\frac{e^{\beta_{0}}}{1+e^{\beta_{0}}}\right)\left(\frac{1}{1+e^{\beta_{0}+\beta_{1}}}\right)}=\frac{e^{\beta_{0}+\beta_{1}}}{e^{\beta_{0}}}=\frac{e^{\beta_{0}} e^{\beta_{1}}}{e^{\beta_{0}}}=e^{\beta_{1}}
$$


Assim, $\beta_{1}$ é interpretado como o logaritmo do $O R$ e, considerando a propriedade de invariância das estimativas de MV às transformações monótonas, uma estimativa do $O R$ é dada por $\widehat{O R}=e^{\widehat{\beta_{1}}}$.

Considerando o modelo de regressão logística múltipla com $k$ variáveis, ou seja, $\mathbf{X}=$ $\left(X_{1}, X_{2}, \ldots, X_{k}\right)^{\prime}$, tem-se que $\beta=\left(\beta_{0}, \beta_{1}, \beta_{2}, \ldots, \beta_{k}\right)^{\prime}$ é o vetor de parâmetros desconhecidos. O OR associado à $i$-ésima variável, ajustado pelas demais variáveis presentes no vetor $\mathbf{X}$, é estimado por $e^{\widehat{\beta}_{i}}$.

\subsection{REGRESSÃO BINÁRIA COM RESPOSTA CONTÍNUA}

No modelo usual de regressão binária, a variável dependente $Y_{i}$ assume o valor 1 para "sucesso" de um evento e 0 para o "fracasso", sendo $i=1, \ldots, n$. Dessa forma, o risco $\pi_{i}$ do $i$-ésimo indivíduo nascer com peso abaixo de $2.500 \mathrm{~g}$, por exemplo, é expresso pela probabilidade de $Y_{i}=1$.

De acordo com o objetivo do trabalho, deve-se utilizar a variável contínua, $T_{i}(\mathrm{PN}$, em quilogramas), ao invés da variável indicadora binária, $Y_{i}$. Assim, a variável aleatória contínua, PN, é considerada e a probabilidade de que o PN de um recém-nascido seja inferior ao valor de corte $c=2.500 \mathrm{~g}, \pi_{i}=P\left(T_{i}<c\right)$, deve ser estimada.

Seja $T_{i}$ uma variável contínua, com observações $t_{i}$, e $\mathbf{x}_{i}=\left(1, x_{1 i}, x_{2 i}, \ldots, x_{k i}\right)^{\prime}$ um vetor de observações de $k$ variáveis explanatórias, $x_{1}, x_{2}, \ldots, x_{k}$, para $i=1, \ldots, n$. O modelo usual de regressão linear múltipla tem a forma:

$$
T_{i}=\beta_{0}+\beta_{1} x_{1 i}+\beta_{2} x_{2_{i}}+\ldots+\beta_{k} x_{k_{i}}+\varepsilon_{i}=\mathbf{x}_{i} \boldsymbol{\beta}+\varepsilon_{i}
$$

onde $\beta=\left(\beta_{0}, \beta_{1}, \beta_{2}, \ldots, \beta_{k}\right)^{\prime}$ é um vetor de $k+1$ parâmetros (desconhecidos) e geralmente assume-se que o erro aleatório $\varepsilon_{i}$ segue uma distribuição normal com média igual a zero e variância constante, dada por $\sigma_{\varepsilon}^{2}$. Ao se condiserar que $T_{i}$ tem média $\mu_{i}$, em um contexto de modelos lineares generalizados, expressa-se $g\left(\mu_{i}\right)=\mathbf{x}_{i} \boldsymbol{\beta}$, onde $g$ é chamada função de ligação. 
A distribuição normal ou distribuição Gaussiana é uma das estatísticas mais utilizadas por três razões principais (CASELLA; BERGER, 2001):

- $\quad$ facilidade de tratamento estatístico;

- distribuição em forma simétrica familiar de sino, adaptável em muitos casos;

- $\quad$ segundo o teorema do limite central, essa distribuição pode ser utilizada na aproximação de uma grande variedade de distribuições.

Por facilidade matemática, assumi-se que o PN segue uma distribuição aproximadamente normal, mas outras distribuições de probabilidade (pertencentes à família exponencial) poderão ser utilizadas caso este pressuposto não seja adequado aos dados do SINASC. A função densidade de probabilidade da distribuição normal é representada da seguinte forma:

$$
f\left(t \mid \mu, \sigma^{2}\right)=\frac{1}{\sqrt{2 \pi \sigma^{2}}} \exp \left[\frac{(t-\mu)^{2}}{-2 \sigma^{2}}\right], \quad-\infty<t<\infty
$$

onde $\mu$ é a média e $\sigma^{2}$ é a variância.

Seja $T_{i}$ variável aleatória contínua com distribuição normal $(\mathrm{PN})$, o risco de uma criança nascer com peso menor que um ponto de corte conhecido $c$ é:

$$
\pi_{i}=P\left(T_{i}<c\right)=P\left(Z_{i}<\frac{c-\mu_{i}}{\sigma}\right)=\Phi\left(\frac{c-\mu_{i}}{\sigma}\right)
$$

onde $Z_{i}$ segue uma distribuição normal padrão e $\Phi(a)$ é dado por:

$$
\Phi(a)=\int_{-\infty}^{a} \frac{1}{\sqrt{2 \pi}} \exp \left(\frac{t^{2}}{-2}\right) d t
$$

O modelo utilizado é $\pi_{i}=g^{-1}\left(\mathbf{X}_{i} \boldsymbol{\beta}\right)$, ou seja:

$$
g\left[\Phi\left(\frac{c-\mu_{i}}{\sigma}\right)\right]=\mathbf{X}_{i} \boldsymbol{\beta}
$$

Dessa forma, tem-se $\Phi\left(\frac{c-\mu_{i}}{\sigma}\right)=g^{-1}\left(\mathbf{X}_{i} \boldsymbol{\beta}\right)$, isto é, $\frac{c-\mu_{i}}{\sigma}=\Phi^{-1}\left[g^{-1}\left(\mathbf{X}_{i} \boldsymbol{\beta}\right)\right]$, e, conse- 
quentemente, $\mu_{i}=c-\sigma \Phi^{-1}\left[g^{-1}\left(\mathbf{X}_{i} \boldsymbol{\beta}\right)\right]$.

Se $T_{i} \sim N\left(\mu_{i}, \sigma^{2}\right)$, a função de verossimilhança para $\boldsymbol{\beta}$ e $\sigma$, é dada por:

$$
\begin{aligned}
L(\boldsymbol{\beta}, \sigma) & =\left(2 \pi \sigma^{2}\right)^{-\frac{n}{2}} \exp \left[-\sum_{i=1}^{n} \frac{\left(t_{i}-\mu_{i}\right)^{2}}{2 \sigma^{2}}\right] \\
& =\left(2 \pi \sigma^{2}\right)^{-\frac{n}{2}} \exp \left\{-\sum_{i=1}^{n} \frac{\left[t_{i}+\sigma \Phi^{-1}\left[g^{-1}\left(\mathbf{X}_{i} \beta\right)\right]-c\right]^{2}}{2 \sigma^{2}}\right\}
\end{aligned}
$$

Então, o logaritmo de $L(\boldsymbol{\beta}, \sigma)$ é dado por:

$$
\begin{aligned}
\ln L(\boldsymbol{\beta}, \sigma) & =-\frac{n}{2} \ln \left(2 \pi \sigma^{2}\right)-\frac{1}{2 \sigma^{2}} \sum_{i=1}^{n}\left[t_{i}+\sigma \Phi^{-1}\left[g^{-1}\left(\mathbf{X}_{i} \beta\right)\right]-c\right]^{2} \\
& =-\frac{n}{2} \ln \left(2 \pi \sigma^{2}\right)-\frac{1}{2 \sigma^{2}} \sum_{i=1}^{n}\left(t_{i}+\sigma \theta_{i}-c\right)^{2}
\end{aligned}
$$

onde $\theta_{i}=\frac{c-\mu_{i}}{\sigma}=\Phi^{-1}\left[g^{-1}\left(\mathbf{X}_{i} \beta\right)\right]$ e $T_{i} \sim N\left(\sigma \theta_{i}+c, \sigma^{2}\right)$.

A estimativa de MV para $\sigma$ é obtida igualando a zero a derivada de (42) em relação a $\sigma$. Tem-se:

$$
\frac{\partial \ln L(\boldsymbol{\beta}, \sigma)}{\partial \sigma}=-\frac{n}{\sigma}-\frac{1}{2 \sigma^{3}}\left[\sigma \sum_{i=1}^{n} 2 \theta_{i}\left(t_{i}+\sigma \theta_{i}-c\right)-2 \sum_{i=1}^{n}\left(t_{i}+\sigma \theta_{i}-c\right)^{2}\right]=0
$$

Esta equação equivale a:

$$
n \sigma^{2}+\sigma \sum_{i=1}^{n} \theta_{i}\left(t_{i}+\sigma \theta_{i}-c\right)-\sum_{i=1}^{n}\left(t_{i}+\sigma \theta_{i}-c\right)^{2}=0
$$

Considerando que $\sigma \sum_{i=1}^{n} \theta_{i}\left(t_{i}+\sigma \theta_{i}-c\right)=\sigma \sum_{i=1}^{n}\left(t_{i} \theta_{i}+\sigma \theta_{i}^{2}-c \theta_{i}\right)=\sigma \sum_{i=1}^{n}\left(t_{i}-c\right) \theta_{i}+$ $\sigma^{2} \sum_{i=1}^{n} \theta_{i}^{2}$ e que $\sum_{i=1}^{n}\left(t_{i}+\sigma \theta_{i}-c\right)^{2}=\sum_{i=1}^{n}\left(t_{i}-c\right)^{2}+2 \sigma \sum_{i=1}^{n} \theta_{i}\left(t_{i}-c\right)+\sigma^{2} \sum_{i=1}^{n} \theta_{i}^{2}$, a expressão (44) corresponde a:

$$
n \sigma^{2}-\sigma \sum_{i=1}^{n} \theta_{i}\left(t_{i}-c\right)-\sum_{i=1}^{n}\left(t_{i}-c\right)^{2}=0
$$


Da tradicional "fórmula de Báskara", tem-se que o estimador $\widehat{\sigma}$ de MV de $\sigma$ é dado por:

$$
\widehat{\sigma}=\frac{\sum_{i=1}^{n} \widehat{\theta}_{i}\left(t_{i}-c\right)+\sqrt{\left[\sum_{i=1}^{n} \widehat{\theta}_{i}\left(t_{i}-c\right)\right]^{2}+4 n \sum_{i=1}^{n}\left(t_{i}-c\right)^{2}}}{2 n} .
$$

sendo $\widehat{\theta}_{i}=\Phi^{-1}\left[g^{-1}\left(\widehat{\beta}_{0}+\widehat{\beta}_{1} x_{1 i}+\widehat{\beta}_{2} x_{2_{i}}+\ldots+\widehat{\beta}_{k} x_{k_{i}}\right)\right]$ e $\widehat{\beta}_{0}, \widehat{\beta}_{1}, \widehat{\beta}_{2}, \ldots, \widehat{\beta}_{k}$ respectivamente os estimadores de MV de $\beta_{0}, \beta_{1}, \beta_{2}, \ldots, \beta_{k}$. A derivada de $\ln L(\boldsymbol{\beta}, \sigma)$ em relação a $\beta_{j}$ $(j=0,1, \ldots, k)$ é dada por:

$$
\begin{aligned}
\frac{\partial \ln L(\boldsymbol{\beta}, \sigma)}{\partial \beta_{j}} & =\frac{1}{\sigma^{2}} \sum_{i=1}^{n}\left(t_{i}+\sigma \theta_{i}-c\right) \frac{\partial \theta_{i}}{\partial \beta_{j}} \\
& =\frac{1}{\sigma^{2}} \sum_{i=1}^{n}\left(t_{i}+\sigma \theta_{i}-c\right) \frac{\partial\left\{\Phi^{-1}\left[g^{-1}\left(\mathbf{X}_{i} \boldsymbol{\beta}\right)\right]\right\}}{\partial \beta_{j}}
\end{aligned}
$$

A derivada de inversa de $\Phi$ é dada por:

$$
\frac{\partial\left[\Phi^{-1}(\psi)\right]}{\partial \psi}=\frac{1}{\varphi\left[\Phi^{-1}(\psi)\right]}
$$

onde $\varphi$ é a função densidade de probabilidade de uma variável aleatória com distribuição normal padrão, considerando que $\Phi$ é uma função monótona e contínua. Assim, estimativas de MV para $\beta_{j}$ são obtidas da expressão:

$$
\sum_{i=1}^{n} \frac{\frac{t_{i}-c}{\widehat{\sigma}}+\Phi^{-1}\left[g^{-1}\left(\mathbf{x}_{i} \boldsymbol{\beta}\right)\right]}{\varphi\left\{\Phi^{-1}\left[g^{-1}\left(\mathbf{x}_{i} \boldsymbol{\beta}\right)\right]\right\}} \frac{\partial\left[g^{-1}\left(\mathbf{x}_{i} \boldsymbol{\beta}\right)\right]}{\partial\left(\mathbf{x}_{i} \boldsymbol{\beta}\right)} \frac{\partial \mathbf{x}_{i} \boldsymbol{\beta}}{\partial \beta_{j}}=0
$$

tal que $\mathbf{x}_{i}$ é o vetor das observações amostrais de $\mathbf{X}_{i}$. Observa-se que a solução desta expressão depende da escolha da função de ligação $g()$. Algumas possibilidades para $g()$ são apresentadas a seguir. 


\subsubsection{Função de ligação logito}

Sendo $\pi\left(x_{i}\right)=P\left(T_{i}>c \mid X_{i}\right)$, a função de ligação logito é dada por:

$$
g\left[\pi\left(x_{i}\right)\right]=\ln \frac{\pi\left(x_{i}\right)}{1-\pi\left(x_{i}\right)}=\mathbf{X}_{i} \boldsymbol{\beta}, \quad i=1, \ldots, n
$$

No caso de uma única variável explanatória $X_{1}$, temos $g\left[\pi_{i}\left(X_{1 i}\right)\right]=\beta_{0}+\beta_{1} x_{1 i}$. Se $X_{1}$ é uma variável binária, assumindo valores 0 ou 1 , para $i=1, \ldots, n$ tem-se:

$$
g\left[\pi_{i}\left(X_{1 i}=1\right)\right]=\ln \frac{\pi_{i}\left(X_{1 i}=1\right)}{1-\pi_{i}\left(X_{1 i}=1\right)}=\ln \frac{P\left(T_{i}>c \mid X_{1 i}=1\right)}{P\left(T_{i} \leq c \mid X_{1 i}=1\right)}=\beta_{0}+\beta_{1}
$$

e:

$$
g\left[\pi_{i}\left(X_{1 i}=0\right)\right]=\ln \frac{\pi_{i}\left(X_{1 i}=0\right)}{1-\pi_{i}\left(X_{1 i}=0\right)}=\ln \frac{P\left(T_{i}>c \mid X_{1 i}=0\right)}{P\left(T_{i} \leq c \mid X_{1 i}=0\right)}=\beta_{0} .
$$

Ao interpretar-se a razão $P\left(Y_{i}>c \mid X_{1 i}=x_{1 i}\right) / P\left(Y_{i} \leq c \mid X_{1 i}=x_{1 i}\right)$ como o odds para o evento $Y_{i}>c$ condicionado a $X_{1 i}=x_{1 i}$, temos de (51) e (52) as expressões:

$$
\frac{P\left(T_{i}>c \mid X_{1 i}=1\right)}{P\left(T_{i} \leq c \mid X_{1 i}=1\right)}=e^{\beta_{0}+\beta_{1}} \quad \text { e } \quad \frac{P\left(T_{i}>c \mid X_{1 i}=0\right)}{P\left(T_{i} \leq c \mid X_{1 i}=0\right)}=e^{\beta_{0}}
$$

Assim:

$$
\frac{P\left(T_{i}>c \mid X_{1 i}=1\right)}{P\left(T_{i} \leq c \mid X_{1 i}=1\right)}\left[\frac{P\left(T_{i}>c \mid X_{1 i}=0\right)}{P\left(T_{i} \leq c \mid X_{1 i}=0\right)}\right]^{-1}=\frac{e^{\beta_{0}+\beta_{1}}}{e^{\beta_{0}}}=e^{\beta_{1}}
$$

ou seja, em um contexto epidemiológico, o parâmetro $\beta_{1}$ é interpretado como o logaritmo da razão de $O d d s(O R)$. Se $\beta_{1}=0$, não tem-se evidências de associação entre $X_{1}$ e o evento $Y_{i}>c$. Uma vantagem do uso desta função de ligação é que temos necessariamente $0<R_{i}\left(X_{1 i}=x_{1 i}\right)<1$, considerando $R_{i}\left(X_{1 i}=x_{1 i}\right)$ uma probabilidade.

De (50), tem-se:

$$
g^{-1}\left(\mathbf{X}_{i} \boldsymbol{\beta}\right)=\frac{\exp \left(\mathbf{X}_{i} \boldsymbol{\beta}\right)}{1+\exp \left(\mathbf{X}_{i} \boldsymbol{\beta}\right)},
$$


e consequentemente:

$$
\frac{\partial\left[g^{-1}\left(\mathbf{X}_{i} \boldsymbol{\beta}\right)\right]}{\partial\left(\mathbf{X}_{i} \boldsymbol{\beta}\right)}=\frac{\exp \left(\mathbf{X}_{i} \boldsymbol{\beta}\right)}{\left[1+\exp \left(\mathbf{X}_{i} \boldsymbol{\beta}\right)\right]^{2}}
$$

Assim, a expressão (49) é reescrita como:

$$
\sum_{i=1}^{n} \frac{\frac{t_{i}-c}{\widehat{\sigma}}+\Phi^{-1}\left[g^{-1}\left(\mathbf{x}_{i} \boldsymbol{\beta}\right)\right]}{\varphi\left\{\Phi^{-1}\left[g^{-1}\left(\mathbf{x}_{i} \boldsymbol{\beta}\right)\right]\right\}} \frac{x_{i j} \exp \left(\mathbf{x}_{i} \boldsymbol{\beta}\right)}{\left[1+\exp \left(\mathbf{x}_{i} \boldsymbol{\beta}\right)\right]^{2}}=0
$$

tal que $x_{i j}=1$ se $j=0$.

\subsubsection{Função de ligação logarítmica}

A função de ligação logarítmica é dada por:

$$
g\left[\pi\left(x_{i}\right)\right]=\ln \pi\left(x_{i}\right)=\mathbf{X}_{i} \boldsymbol{\beta}, \quad i=1, \ldots, n .
$$

No caso de uma única variável explanatória $X_{1}$, assumindo valores 0 ou 1 para $i=$ $1, \ldots, n$, tem-se:

$$
g\left[\pi_{i}\left(X_{1 i}=1\right)\right]=\ln P\left(T_{i}>c \mid X_{1 i}=1\right)=\beta_{0}+\beta_{1}
$$

e:

$$
g\left[\pi_{i}\left(X_{1 i}=0\right)\right]=\ln P\left(T_{i}>c \mid X_{1 i}=0\right)=\beta_{0}
$$

Assim, $e^{\beta_{1}}=P\left(T_{i}>c \mid X_{1 i}=1\right) / P\left(T_{i}>c \mid X_{1 i}=0\right)$, sendo o parâmetro $\beta_{1}$ agora interpretado como o logaritmo do risco relativo.

De (58), temos $g^{-1}\left(\mathbf{X}_{i} \boldsymbol{\beta}\right)=\exp \left(\mathbf{X}_{i} \boldsymbol{\beta}\right)$, e:

$$
\frac{\partial\left[g^{-1}\left(\mathbf{X}_{i} \boldsymbol{\beta}\right)\right]}{\partial\left(\mathbf{X}_{i} \boldsymbol{\beta}\right)}=\exp \left(\mathbf{X}_{i} \boldsymbol{\beta}\right)
$$


Assim, a expressão (49) é reescrita como:

$$
\sum_{i=1}^{n} \frac{\frac{t_{i}-c}{\widehat{\sigma}}+\Phi^{-1}\left[g^{-1}\left(\mathbf{x}_{i} \boldsymbol{\beta}\right)\right]}{\varphi\left\{\Phi^{-1}\left[g^{-1}\left(\mathbf{x}_{i} \boldsymbol{\beta}\right)\right]\right\}} x_{i j} \exp \left(\mathbf{x}_{i} \boldsymbol{\beta}\right)=0
$$

tal que $x_{i j}=1$ se $j=0$.

\subsubsection{Função de ligação identidade}

A função de ligação identidade é dada por:

$$
g\left[\pi\left(x_{i}\right)\right]=\pi\left(x_{i}\right)=\mathbf{X}_{i} \boldsymbol{\beta}, \quad i=1, \ldots, n .
$$

No caso de uma única variável explanatória $X_{1}$, assumindo valores 0 ou 1 para $i=$ $1, \ldots, n$, tem-se:

$$
g\left[\pi_{i}\left(X_{1 i}=1\right)\right]=P\left(T_{i}>c \mid X_{1 i}=1\right)=\beta_{0}+\beta_{1}
$$

e:

$$
g\left[\pi_{i}\left(X_{1 i}=0\right)\right]=P\left(T_{i}>c \mid X_{1 i}=0\right)=\beta_{0}
$$

Assim, $\beta_{1}=P\left(T_{i}>c \mid X_{1 i}=1\right)-P\left(T_{i}>c \mid X_{1 i}=0\right)$, ou seja, o parâmetro $\beta_{1}$ é agora interpretado como uma redução absoluta de risco (ou diferença de riscos).

\subsection{CURVA ROC}

A curva ROC (Receiver Operating Characteristic) é um gráfico, no qual o eixo vertical apresenta a taxa de verdadeiros positivos (a sensibilidade) e o eixo horizontal apresenta a taxa de falsos positivos (complemento da especificidade) (MARTINEZ et al, 2003). A curva ROC foi desenvolvida originalmente durante a segunda guerra mundial com o objetivo de quantificar a habilidade dos receptores dos radares em detectar sinais eletrônicos 
(aviões inimigos) dos ruídos (objetos voadores irrelevantes) (COLLINSON, 1998). A partir da década 70, a curva ROC foi amplamente utilizada em diversas áreas biomédicas, especialmente na classificação de indivíduos como doentes ou não doentes. No presente trabalho, a curva ROC foi utilizada na comparação da capacidade preditiva entre o modelo de regressão logística usual e o de regressão com resposta contínua, proposto neste projeto. A seguir, alguns conceitos básicos sobre a curva ROC são apresentados.

A sensibilidade $\left(\mathrm{S}_{E}\right)$ é a probabilidade do modelo classificar o indivíduo como portador de $\mathrm{BPN}$, dado que esse indivíduo realmente nasceu com baixo peso. A especificidade $\left(\mathrm{E}_{S}\right)$ é definida como a probabilidade de o modelo classificar corretamente um recém-nascido como não portador de BPN. No contexto do presente estudo, o PN é a variável resposta, e dependendo do ponto de corte, um indivíduo pode ser classificado como BPN (apresentar o peso abaixo do ponto de corte estabelecido) ou peso normal (igual ou acima do ponto de corte). Desta forma, para diferentes valores do ponto de corte, pode-se estimar seus valores correspondentes da sensibilidade e da especificidade. Uma curva ROC é assim constituída pelos resultantes pares $\mathrm{S}_{E}$ e $1-\mathrm{E}_{S}$.

A área sob a curva ROC, AUC (area under the curve), é uma medida resumo muito utilizada na classificação e/ou na comparação do desempenho dos testes ou modelos de interesse. Essa medida é obtida levando em consideração todas as medidas de $\mathrm{S}_{E}$ e $1-$ $\mathrm{E}_{S}$ relativas a cada um dos valores do ponto de corte estipulados. Quanto maior a AUC, mais a curva se aproxima do canto superior esquerdo do gráfico $(\mathrm{AUC} \rightarrow 1)$, e maior a capacidade do modelo em classificar corretamente indivíduos como doente (BPN, por exemplo) ou não doente. Para um modelo totalmente incapaz de distinguir um indivíduo de doente de um não doente, a curva ROC estaria sobreposta à diagonal que atravessa as coordenadas $(0,0)$ e $(1,1)$ e sua AUC seria igual a 0,5. Quando apresentamos em um mesmo gráfico duas curvas ROC associados a dois diferentes modelos, uma imediata comparação de desempenhos é permitida: a curva superior representa o modelo com melhor desempenho de classificação (MARTINEZ et al, 2003). 


\subsection{IMPLEMENTAÇÃO}

Na implementação computacional do modelo proposto, foram utilizados o programa $\mathrm{R}$ (disponível no site The $R$ Project for Statistical Computing) e o SAS.

\subsection{EXEMPLOS DA ESTIMAÇÃO POR MÁXIMA VEROSSIMILHANÇA}

\subsubsection{Exemplo com amostra de dados de RN}

Para ilustrar o uso do modelo proposto, uma amostra de 50 recém-nascidos de ambos os sexos, sendo 13 com PN inferior a $2.500 \mathrm{~g}$ (com a proporção de $26 \%$ de BPN), foi selecionada aleatoriamente dentro dos registros do SINASC do ano de 1999, de uma população de nascidos vivos dos municípios Rio Branco e Feijó (AC). A escolha destes municípios foi arbitrária. Por simplicidade, seja uma única variável independente, o tipo de parto, definida como $X=1$ para parto vaginal (normal) e $X=0$ para parto cesariano. Os dados são exibidos na Tabela 2. A variável dependente é PN do bebê expresso em valores contínuos em quilogramas. Considerando uma única variável independente, o vetor $\boldsymbol{\beta}$ é composto por dois elementos: $\beta_{0}$ e $\beta_{1}$.

Tabela 2: Peso ao nascer, de uma amostra de 50 recém-nascidos dos municípios Rio Branco e Feijó (AC), segundo tipo de parto ( $\mathrm{X}=1$, parto vaginal, $\mathrm{X}=0$, parto cesariano)

\begin{tabular}{|c|c|c|}
\hline $\mathrm{X}$ & Peso ao nascer (kg) & Média (g) \\
\hline $\mathrm{X}=0$ & $\begin{array}{l}2,6503,0003,9003,8003,8003,0002,4702,1502,4503,050 \\
2,5003,8003,1303,5502,190 \quad 1,580\end{array}$ & 2938,75 \\
\hline $\mathrm{X}=1$ & $\begin{array}{llllllllll}2,800 & 3,800 & 3,300 & 2,900 & 3,000 & 2,900 & 3,600 & 4,000 & 3,700 & 3,000 \\
3,800 & 1,800 & 3,000 & 3,099 & 2,500 & 3,800 & 3,300 & 2,200 & 2,750 & 2,400 \\
3,250 & 3,150 & 3,380 & 3,200 & 1,640 & 3,350 & 3,200 & 2,300 & 1,620 & 3,550 \\
2,270 & 3,250 & 1,920 & 2,900\end{array}$ & 2959,68 \\
\hline
\end{tabular}

Utilizando o procedimento PROC NLP (NonLinear Programming) do programa SAS, obtivemos por métodos numéricos estimativas dos valores que maximizam a função de log-verossimilhança $\ln L\left(\beta_{0}, \beta_{1}, \sigma\right)$, onde $c=2,5 \mathrm{~kg}$. As estimativas de $M V$ assim obtidas são $\widehat{\beta}_{0}=1,1081, \widehat{\beta}_{1}=0,0552$ e $\hat{\sigma}=0,645136 \mathrm{~kg}$, considerando uma função de ligação 
logito. Para ilustrar a forma da função de log-verossimilhança, fixamos $\sigma$ em 0,645136, e a Figura 2 apresenta um gráfico tridimensional de $\ln L\left(\beta_{0}, \beta_{1}, \sigma=0,645136\right)$ segundo valores de $\beta_{0}$ e $\beta_{1}$.

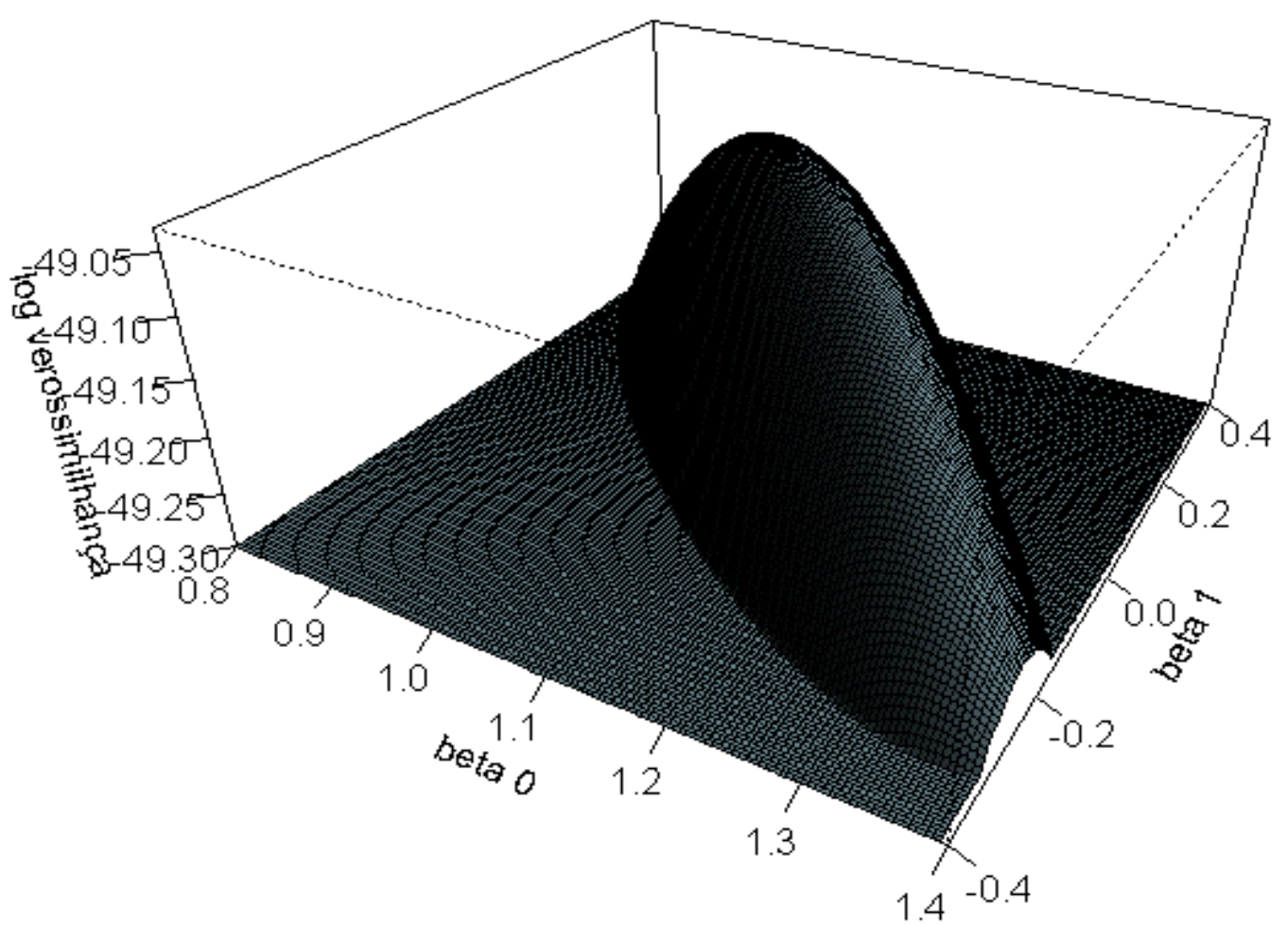

Figura 2: Distribuição de valores de $\beta_{0}, \beta_{1}$ e $\ln L\left(\beta_{0}, \beta_{1}, \sigma=0,645136\right)$.

A Figura 3 apresenta um gráfico de contornos de $\ln L\left(\beta_{0}, \beta_{1}, \sigma=0,645136\right)$, desenvolvido com o auxílio do programa R. A figura delineia o valor obtido do logaritmo da verossimilhança a partir dos pontos do vetor $\beta$ dentro de seus determinados intervalos. $\mathrm{O}$ ponto máximo para $\beta_{0}$ e $\beta_{1}$ é marcado na figura. Este ponto, por sua vez, é a solução da função de $M V$ nesse caso.

As médias amostrais para os recém nascidos classificados cuja forma de término de parto é cesariana ou normal são 2,9387 kg e 2,9597 kg, respectivamente (ver Tabela 2). As médias estimadas pelo modelo, dadas por:

$$
\mu_{i}=\hat{\sigma} \Phi^{-1}\left[g^{-1}\left(\hat{\beta}_{0}+\hat{\beta}_{1} x_{i}\right)\right]+c
$$




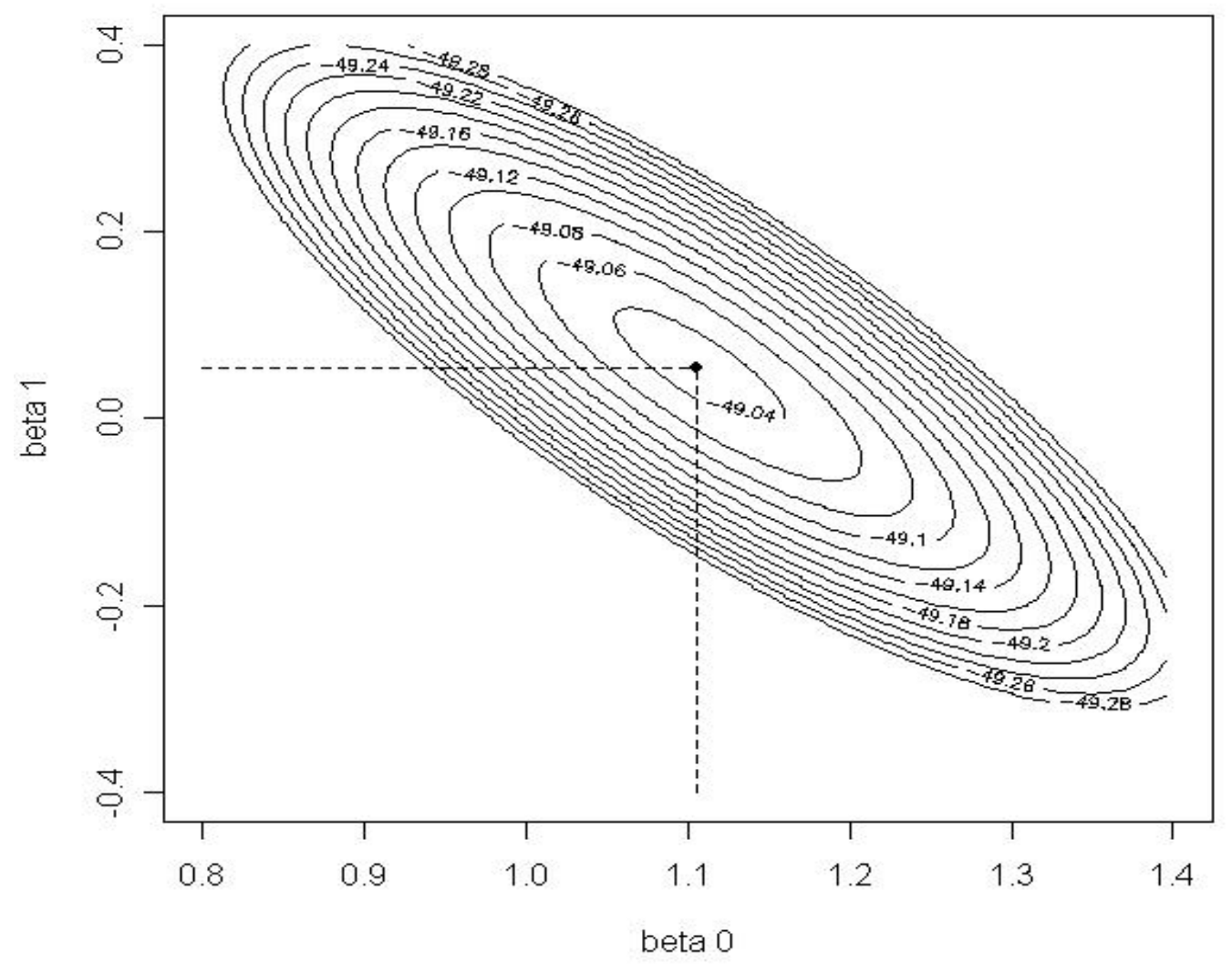

Figura 3: Contorno de $\beta_{0}$ versus $\beta_{1}$ para os valores de logaritmo de $L(\beta, \sigma)$ 
são, respectivamente, $2,9378 \mathrm{~kg}$ e $2,9587 \mathrm{~kg}$, onde $c=2,5 \mathrm{~kg}$. Observa-se assim, que as estimativas obtidas pelo modelo e as obtidas diretamente da amostra (ver Tabela 2) são bastante próximas.

Foram obtidos também resultados de $O R$ e seu respectivo $I C$ de $95 \%$ a fim de estudar a associação entre o tipo de parto e o BPN. Baseado nesse conjunto de dados, o parto normal, ou seja, $X=1$, foi considerado como referência para o cálculo do $O R$. Para o modelo da regressão logística usual, o referente conjunto de dados possui $O R$ de 1,48 (0,39-5,54). Para o modelo proposto, o $O R$ é 1,06 (0,00-2,13).

\subsubsection{Exemplo com dados simulados}

Um outro teste para o modelo proposto foi realizado utilizando variáveis aleatórias geradas no ambiente R. Inicialmente a variável aleatória y com a distribuição normal $N(2 ; 0,55)$ e $n=100$ elementos foi gerada. A escolha de todos parâmetros utilizados nesta simulação foi arbitrária. Foi determinado um ponto de corte $c=1,5$, a partir do qual pode-se classificar os elementos do vetor $y$ em dois grupos (grupo 1 para $y<1,5$ e grupo 2 para $y \geq 1,5)$. Em seguida, o vetor $x$ de 100 elementos com a distribuição binomial foi gerado. A probabilidade de sucesso $p$ dessa distribuição segue a seguinte condição:

$$
p_{i}=\frac{e^{\beta_{0}+\beta_{1} *(y-2)}}{1+e^{\beta_{0}+\beta_{1} *(y-2)}}, i=1, \ldots, n, \text { considerando fixos os parâmetros } \beta_{0} \text { e } \beta_{1} \text {. }
$$

Foram escolhidos arbitrariamente os valores dos parâmetros, sendo $\beta_{0}=0,5$ e $\beta_{1}=1,2$. Dessa forma, obteve-se um conjunto de dados de 100 elementos, cuja variável resposta é $y$ e a variável independente é $x$, que assume valores 0 ou 1.

Utilizando esse conjunto de dados, pode-se realizar uma simulação de análise de dados segundo a metodologia proposta. Os resultados obtidos estão apresentados a seguir:

1) A média do $y$ quando $x=0$ é 1,8063 ; quando $x=1$ é 2,1839 ; 
2) A média do y estimada, segundo o modelo de regressão de resposta contínua, quando $x=0$ é 1,$8021 ;$ quando $x=1$ é 2,1834 ;

3) O $O R$ estimado utilizando a regressão logística usual é 5,46, com o $I C$ de $95 \%$ de $(1,57-18,98)$

4) O $O R$ estimado segundo a regressão com resposta contínua é 3,85, com o $I C 95 \%$ de $(3,09-4,62)$.

Pode-se observar que as médias estimadas pelo modelo com resposta contínua são próximas às obtidas diretamente dos dados simulados. A estimativa do $O R$ obtidas pelo modelo de regressão logística usual é maior que aquela obtida do modelo baseado em resposta contínua. Pode-se notar também uma diferença entre os ICs estimados pelos dois modelos, já que a estimativa obtida a partir do modelo proposto possui um intervalo com menor amplitude em relação ao resultado obtido utilizando o modelo de regressão usual. 


\section{RESULTADOS}

Para a análise de dados, foi selecionado do banco de dados de registros de nascidos vivos em 2005 do Município de Ribeirão Preto. Foi encontrado um total de quase 10.000 registros. Segundo o critério de exclusão, além de excluir dados incompletos, os nascidos vivos portadores de alguma anomalia congênita, os nascidos com idade gestacional de menos de 32 semanas e as gravidezes múltiplas (duplas, triplas ou mais) foram desconsiderados. A justificativa da exclusão encontra-se no Capítulo 3, Seção "Banco de dados". Após o procedimento de filtro de dados, foram considerados 8.751 indivíduos para a análise, com a proporção de BPN de 7,5\%. Entre esse total de registros, 30\% dos dados foram utilizados para levantar as potenciais variáveis de risco ao BPN e 70\% dos dados restantes foram utilizados na implementação das curvas ROC para avaliar os resultados obtidos. Dessa forma, um algoritmo de sorteio baseado na geração de números binários com probabilidade de sucesso de $30 \%$ foi elaborado para separar os dados nos seguintes grupos: grupo de análise e grupo de teste. Assim, dados de 2.601 indivíduos foram alimentados nos algoritmos de cálculo de $O R$ para levantamento de fatores de risco para BPN. Nesse conjunto de dados, foram encontrados 204 BPN, ou seja, a prevalência de BPN para essa amostra de dados é 78 em cada 1000 indivíduos. Foram utilizados 6.150 registros nos algoritmos de comparação de resultados através das curvas ROC. A Figura 4 apresenta o histgrama desse conjunto de dados.

Devido à necessidade de conhecer o comportamento de cada variável independente em relação ao PN, vários gráficos de box-plot foram construídos utilizando todos os 8.751 registros. A Figura 5 apresenta os gráficos de box plot do PN segundo as variáveis situação conjugal da mãe, tipo de parto, primiparidade e escolaridade da mãe. A linha tracejada horizontal representa a linha de corte que separa BPN dos demais, ou seja, ela assume o valor do PN de $2.500 \mathrm{~g}$ e os indivíduos com BPN encontram-se abaixo desta linha. Através do gráfico da situação conjugal, pode-se notar que, na categoria separada/viúva, há uma proporção relativamente maior de BPN, mas a média de PN é menor no grupo de mães de união consensual. Em relação ao tipo de parto, não se percebe diferenças da distribuição 


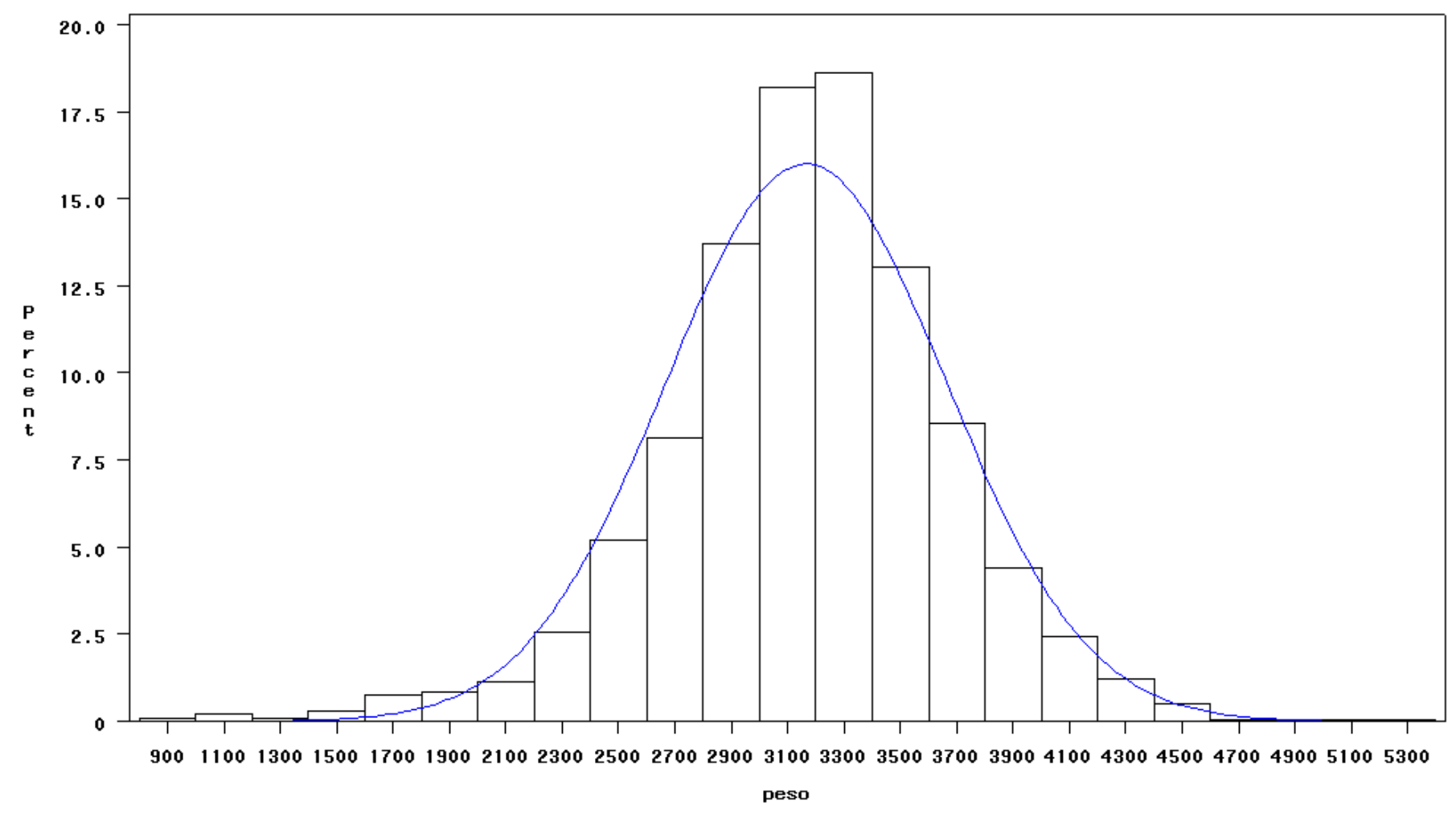

Figura 4: Histograma do peso ao nascer, SINASC - Ribeirão Preto (2005). 

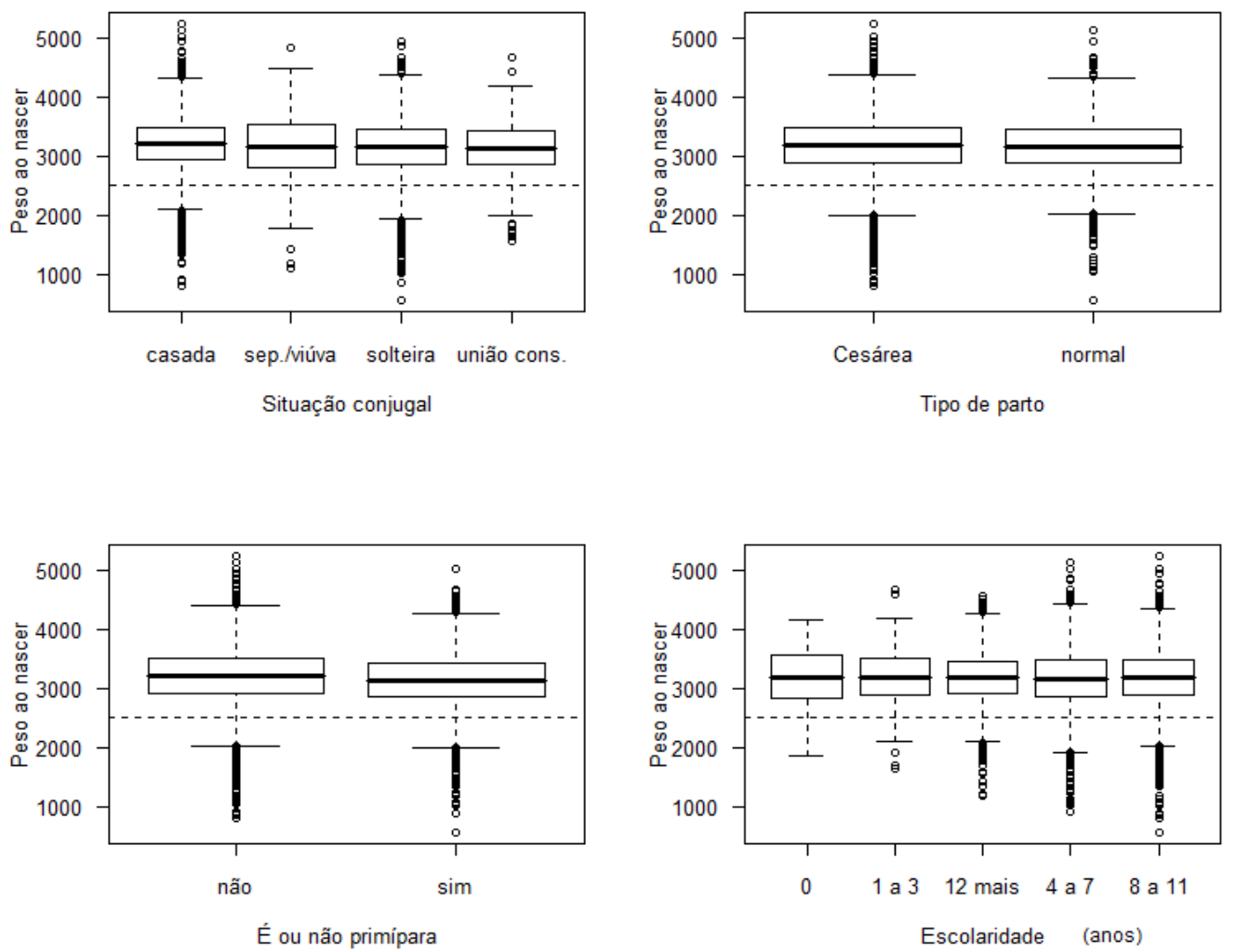

Figura 5: Box plot do PN em relação à situação conjugal e escolaridade da mãe, ao tipo de parto e se é primípara, SINASC - Ribeirão Preto (2005) 


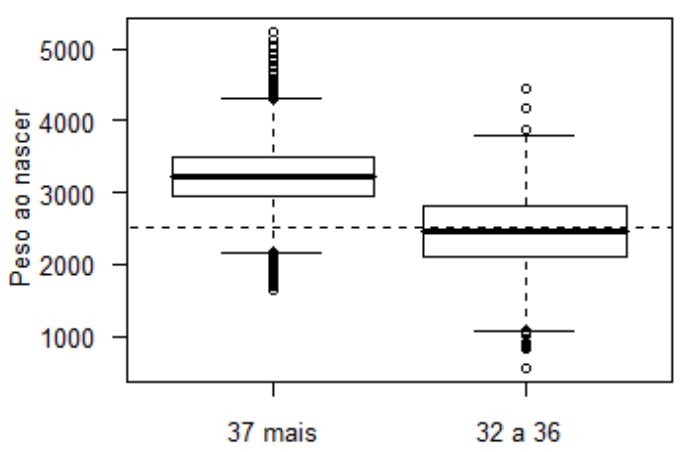

Duração da gestação (semanas)

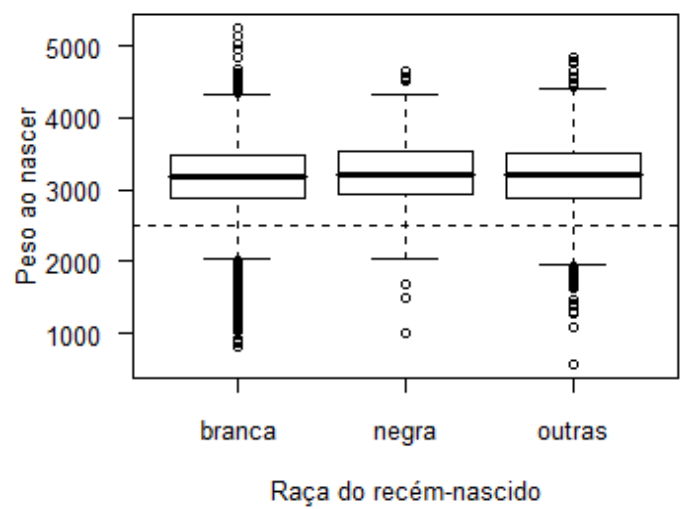

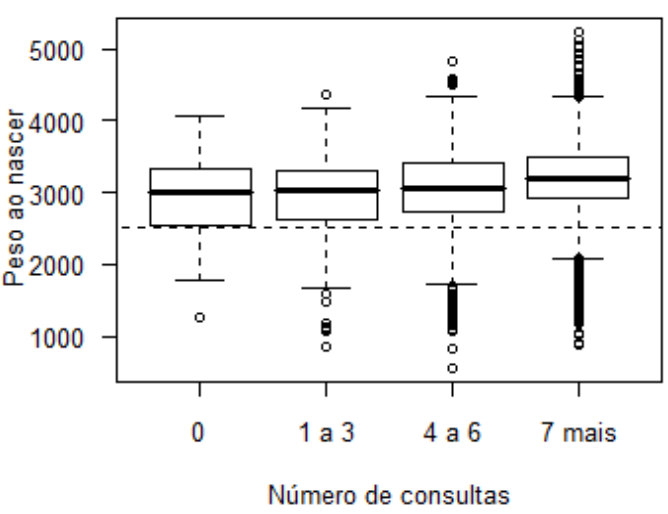

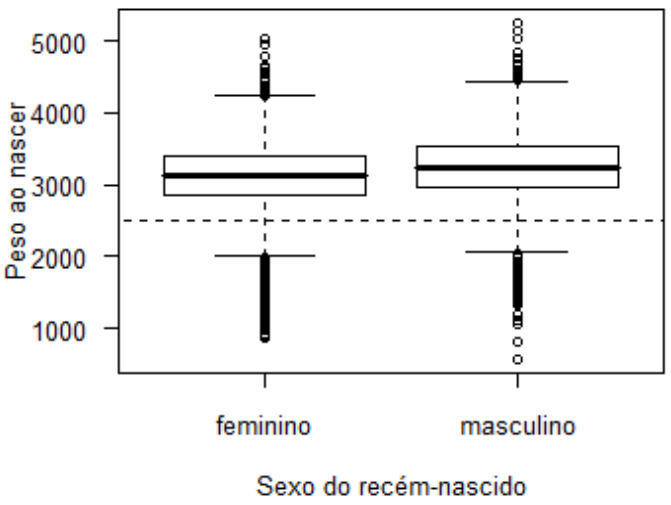

Figura 6: Box plot do PN de acordo com a duração da gestação, o número de consultas pre-natais, a raça e o sexo do RN, SINASC - Ribeirão Preto (2005)

do PN entre bebês nascidos de parto normal e aqueles nascidos de parto cesariano. Para mulheres primíparas, seus filhos possuem uma distribuição de PN ligeiramente menor comparando com aqueles nascidos a partir do segundo parto. Em termos de escolaridade da mãe, a média de PN assume praticamente um mesmo valor, porém, entre mães com nenhum ou 4 a 7 anos de estudo, observa-se uma proporção maior de BPN.

A Figura 6 demonstra os gráficos de box plot do PN segundo duração da gestação, número de consultas de pré-natal, grupo racial e sexo do recém-nascido. Uma diferença relativamente grande pode ser notada comparando o comportamento da variável PN quando a duração da gestação é de menos de 37 semanas com os pesos referentes às durações da gestação maiores. Conforme aumenta a quantidade de consultas de pré-natal participadas 


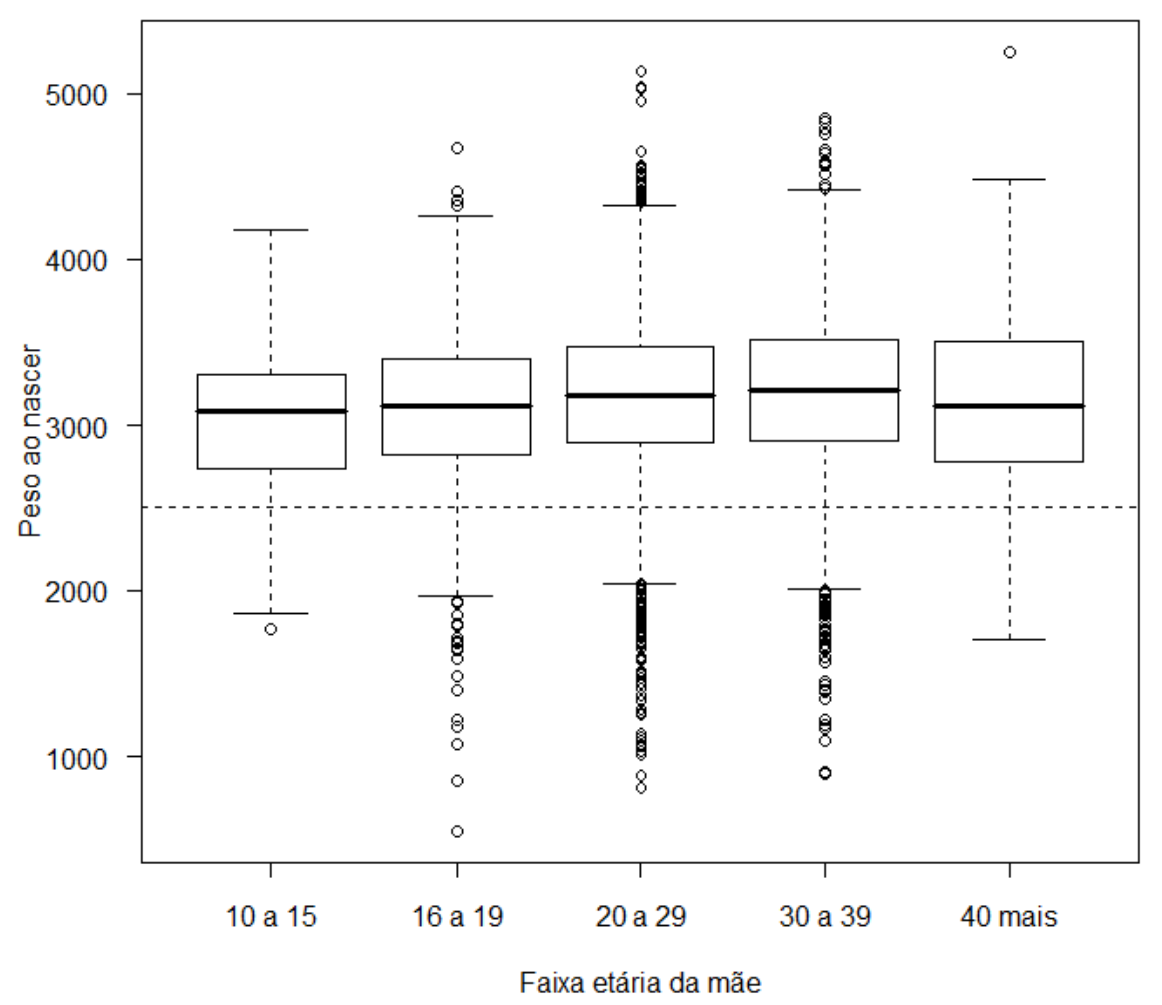

Figura 7: Box plot do PN referente à faixa etária da mãe, SINASC - Ribeirão Preto (2005)

pela mãe, aumenta também a média do PN dos seus filhos. Podemos observar também, na Figura 6, uma pequena diferença do PN entre recém-nascidos masculinos e femininos, estes, com pesos ligeiramente mais baixos. A Figura 7 apresenta uma visão geral sobre a distribuição de faixa etária das mães em relação ao PN dos seus filhos. O gráfico demonstra que, para mães entre 20 e 39 anos, a média do PN de seus filhos é maior em relação aos outros grupos. Além disso, nota-se uma maior proporção de bebês com BPN quando suas mães têm menos de 15 anos ou mais de 40 anos.

Utilizando o PROC LOGISTIC do pacote estatístico SAS, detectamos alguns fatores de risco para $\mathrm{BPN}$, com seus respectivos $O R$ s e intervalos de confiança de $95 \%$ utilizando a regressão logística usual múltipla. A Tabela 3 apresenta os resultados da regressão logística usual simples e múltipla. 
Tabela 3: Resultados da regressão logística usual para dados do SINASC de Ribeirão Preto, 2005

\begin{tabular}{|c|c|c|c|c|}
\hline Variáveis & $P N<2.500 g$ & $P N>=2.500 g$ & $O R$ bruto (IC 95\%) & $O R$ ajustado (IC 95\%) \\
\hline \multicolumn{5}{|c|}{ Situação conjugal da mãe } \\
\hline Solteira & $95(8,6 \%)$ & $1007(91,4 \%)$ & $1,48(1,08-2,01)$ & $1,23(0,80-1,87)$ \\
\hline Casada & $78(6,0 \%)$ & $1220(94,0 \%)$ & 1,00 (ref.) & 1,00 (ref.) \\
\hline Viúva/Sep. & $13(20,6 \%)$ & $50(79,4 \%)$ & $4,07(2,12-7,80)$ & $2,77(1,17-6,60)$ \\
\hline União cons. & $18(13,0 \%)$ & $120(87,0 \%)$ & $2,35(1,36-4,05)$ & $1,93(0,95-3,92)$ \\
\hline \multicolumn{5}{|c|}{ Escolaridade da mãe (anos) } \\
\hline nenhuma & $3(15,8 \%)$ & $16(84,2 \%)$ & $3,20(0,89-11,50)$ & $3,49(0,66-18,45)$ \\
\hline 1 a 3 & $6(7,7 \%)$ & $72(92,3 \%)$ & $1,42(0,58-3,50)$ & $1,07(0,31-3,62)$ \\
\hline 4 a 7 & $79(10,2 \%)$ & $699(89,8 \%)$ & $1,93(1,28-2,91)$ & $2,08(1,16-3,73)$ \\
\hline 8 a 11 & $81(7,4 \%)$ & $1013(92,6 \%)$ & $1,36(0,91-2,05)$ & $1,41(0,84-2,38)$ \\
\hline$\geq 12$ & $35(5,5 \%)$ & $597(94,5 \%)$ & 1,00 (ref.) & 1,00 (ref.) \\
\hline \multicolumn{5}{|c|}{ Duração da gestação (semanas) } \\
\hline até 36 & $119(53,6 \%)$ & $103(46,4 \%)$ & $31,18(22,16-43,86)$ & $29,86(20,57-43,34)$ \\
\hline$>36$ & $85(3,6 \%)$ & $2294(96,4 \%)$ & 1,00 (ref.) & 1,00 (ref.) \\
\hline \multicolumn{5}{|c|}{ Tipo de parto } \\
\hline normal & $82(7,1 \%)$ & $1070(92,9 \%)$ & 1,00(ref.) & 1,00 (ref.) \\
\hline cesária & $122(8,4 \%)$ & $1327(91,6 \%)$ & $1,20(0,90-1,61)$ & $1,68(1,12-2,52)$ \\
\hline \multicolumn{5}{|c|}{ Número de consultas pré-natal } \\
\hline nenhuma & $6(27,3 \%)$ & $16(72,7 \%)$ & $6,26(2,41-16,30)$ & $5,15(1,46-18,23)$ \\
\hline 1 a 3 & $26(22,6 \%)$ & $89(77,4 \%)$ & $4,88(3,03-7,85)$ & $2,60(1,33-5,08)$ \\
\hline 4 a 6 & $55(14,0 \%)$ & $338(86,0 \%)$ & $2,72(1,93-3,82)$ & $2,04(1,30-3,18)$ \\
\hline$\geq 7$ & $117(5,6 \%)$ & $1965(94,4 \%)$ & 1,00 (ref.) & 1,00 (ref.) \\
\hline \multicolumn{5}{|l|}{ Raça / Cor } \\
\hline branca & $150(7,3 \%)$ & $1898(92,7 \%)$ & $0,83(0,41-1,67)$ & $0,62(0,27-1,44)$ \\
\hline negra & $9(8,7 \%)$ & $94(91,3 \%)$ & 1,00 (ref.) & 1,00 (ref.) \\
\hline outras & $45(10,0 \%)$ & $405(90,0 \%)$ & $1,16(0,55-2,46)$ & $0,95(0,39-2,29)$ \\
\hline \multicolumn{5}{|c|}{ Idade materna (anos) } \\
\hline 10 a 15 & $11(23,4 \%)$ & $36(76,6 \%)$ & $3,99(1,97-8,09)$ & $2,68(1,06-6,80)$ \\
\hline 16 a 19 & $31(8,7 \%)$ & $325(91,3 \%)$ & $1,25(0,82-1,90)$ & $1,13(0,66-1,93)$ \\
\hline 20 a 29 & $98(7,1 \%)$ & $1281(92,9 \%)$ & 1,00 (ref.) & 1,00 (ref.) \\
\hline 30 a 39 & $57(7,5 \%)$ & $700(92,5 \%)$ & $1,06(0,76-1,49)$ & $1,11(0,71-1,70)$ \\
\hline 40 a 49 & $7(11,3 \%)$ & $55(88,7 \%)$ & $1,66(0,74-3,75)$ & $1,23(0,44-3,45)$ \\
\hline \multicolumn{5}{|c|}{ É ou não primeiro filho } \\
\hline Sim & $100(7,2 \%)$ & $1281(92,8 \%)$ & $1,19(1,09-1,59)$ & $1,66(1,10-2,49)$ \\
\hline Não & $104(8,5 \%)$ & $1114(91,5 \%)$ & 1,00 (ref.) & 1,00 (ref.) \\
\hline \multicolumn{5}{|c|}{ Sexo do recém-nascido } \\
\hline Masculino & $87(6,8 \%)$ & $1197(93,2 \%)$ & 1,00 (ref.) & 1,00 (ref.) \\
\hline Feminino & $117(8,9 \%)$ & $1200(91,1 \%)$ & $1,34(1,01-1,79)$ & $1,63(1,14-2,32)$ \\
\hline
\end{tabular}


Tabela 4: Resultados da regressão binária com resposta contínua para dados do SINASC de Ribeirão Preto, 2005

\begin{tabular}{|c|c|c|c|c|c|c|}
\hline \multirow[b]{2}{*}{ Variáveis } & \multicolumn{3}{|c|}{ Regressão simples } & \multicolumn{3}{|c|}{ Regressão múltipla } \\
\hline & $\ln (O R)$ & $\widehat{e p}$ & $O R$ bruto (IC 95\%) & $\ln (O R)$ & $\widehat{e p}$ & $O R$ ajustado (IC 95\%) \\
\hline \multicolumn{7}{|c|}{ Situação conjugal da mãe } \\
\hline Solteira & 0,234 & 0,080 & $1,26(1,11-1,42)$ & 0,088 & 0,095 & $1,09(0,91-1,28)$ \\
\hline Casada & & & 1,00 (ref.) & & & 1,00 (ref.) \\
\hline Viúva/Sep. & 0,590 & 0,331 & $1,80(1,16-2,45)$ & 0,287 & 0,321 & $1,33(0,70-1,96)$ \\
\hline União cons. & 0,602 & 0,177 & $1,83(1,48-2,17)$ & 0,439 & 0,188 & $1,55(1,18-1,92)$ \\
\hline \multicolumn{7}{|c|}{ Escolaridade da mãe (anos) } \\
\hline nenhuma & 0,083 & 0,491 & $1,08(0,12-2,05)$ & $-0,310$ & 0,805 & $0,73(0,00-2,31)$ \\
\hline 1 a 3 & 0,113 & 0,247 & $1,12(0,64-1,60)$ & $-0,063$ & 0,274 & $0,94(0,40-1,48)$ \\
\hline 4 a 7 & 0,247 & 0,106 & $1,28(1,07-1,49)$ & 0,146 & 0,136 & $1,16(0,89-1,42)$ \\
\hline 8 a 11 & 0,271 & 0,097 & $1,31(1,12-1,50)$ & 0,209 & 0,116 & $1,23(1,00-1,46)$ \\
\hline$\geq 12$ & & & 1,00 (ref.) & & & 1,00 (ref.) \\
\hline \multicolumn{7}{|c|}{$\overline{\text { Duração da gestação (semanas) }}$} \\
\hline até 36 & 3,231 & 0,150 & $25,30(25,01-25,60)$ & 3,215 & 0,150 & $24,90(24,61-25,20)$ \\
\hline$>36$ & & & 1,00 (ref.) & & & 1,00 (ref.) \\
\hline \multicolumn{7}{|c|}{ Tipo de parto } \\
\hline normal & & & 1,00 (ref.) & & & 1,00 (ref.) \\
\hline cesária & $-0,129$ & 0,077 & $0,88(0,73-1,03)$ & $-0,027$ & 0,097 & $0,97(0,78-1,16)$ \\
\hline \multicolumn{7}{|c|}{ Número de consultas pré-natal } \\
\hline nenhuma & 1,054 & 0,466 & $2,87(1,96-3,78)$ & 0,733 & 0,571 & $2,08(0,96-3,20)$ \\
\hline 1 a 3 & 1,131 & 0,194 & $3,10(2,72-3,48)$ & 0,687 & 0,220 & $1,99(1,56-2,42)$ \\
\hline 4 a 6 & 0,714 & 0,112 & $2,04(1,82-2,26)$ & 0,608 & 0,120 & $1,84(1,60-2,07)$ \\
\hline$\geq 7$ & & & 1,00 (ref.) & & & 1,00 (ref.) \\
\hline \multicolumn{7}{|l|}{ Raça / Cor } \\
\hline branca & $-0,100$ & 0,202 & $0,9(0,51-1,30)$ & $-0,255$ & 0,215 & $0,77(0,35-1,20)$ \\
\hline negra & & & 1,00 (ref.) & & & 1,00 (ref.) \\
\hline outras & $-0,017$ & 0,219 & $0,98(0,55-1,41)$ & $-0,158$ & 0,229 & $0,85(0,41-1,30)$ \\
\hline \multicolumn{7}{|c|}{ Idade materna (anos) } \\
\hline 10 a 15 & 0,793 & 0,241 & $2,21(1,73-2,68)$ & 0,277 & 0,269 & $1,32(0,79-1,85)$ \\
\hline 16 a 19 & 0,257 & 0,113 & $1,29(1,07-1,51)$ & 0,037 & 0,135 & $1,04(0,77-1,30)$ \\
\hline 20 a 29 & & & 1,00 (ref.) & & & 1,00 (ref.) \\
\hline 30 a 39 & $-0,056$ & 0,093 & $0,95(0,76-1,13)$ & 0,052 & 0,106 & $1,05(0,85-1,26)$ \\
\hline 40 a 49 & 0,014 & 0,302 & $1,01(0,42-1,61)$ & $-0,048$ & 0,289 & $0,95(0,39-1,52)$ \\
\hline \multicolumn{7}{|c|}{ É ou não primeiro filho } \\
\hline Sim & 0,337 & 0,078 & $1,40(1,25-1,55)$ & 0,459 & 0,096 & $1,58(1,39-1,77)$ \\
\hline Não & & & 1,00 (ref.) & & & 1,00 (ref.) \\
\hline \multicolumn{7}{|c|}{ Sexo do recém-nascido } \\
\hline Masculino & & & 1,00 (ref.) & & & 1,00 (ref.) \\
\hline Feminino & 0,529 & 0,079 & $1,70(1,54-1,85)$ & 0,658 & 0,086 & $1,93(1,76-2,10)$ \\
\hline
\end{tabular}


Conforme as equações apresentadas na Sub-seção 3.5, foi elaborado um programa computacional no ambiente SAS com o objetivo de ajustar modelos de resposta contínua e obter os valores estimados de $\widehat{\beta}_{i}$. Para estimar o valor de $O R$ de uma regressão com resposta contínua, o procedimento é o mesmo da regressão logística usual, ou seja, $\widehat{O R}=$ $e^{\widehat{\beta_{i}}}$. A estimativa do intervalo de confiança assintótico de $100(1-\alpha) \%$ para o OR segue a seguinte forma:

$$
\left[\widehat{\beta}_{i}-z_{(1-\alpha / 2)} \widehat{e p}\left(\widehat{\beta}_{i}\right) \quad, \quad \widehat{\beta}_{i}+z_{(1-\alpha / 2)} \widehat{e p}\left(\widehat{\beta}_{i}\right)\right]
$$

A Tabela 4 apresenta os resultados obtidos a partir da regressão binária proposta, com resposta contínua, incluindo as estimativas de $\beta_{i}=\ln \left(O R_{i}\right), \sigma$, o erro padrão $\left(\widehat{e p}\left(\widehat{\beta}_{i}\right)\right)$, $O R$ simples e ajustado e seus respectivos intervalos de confiança de $95 \%$, sendo $\widehat{\beta}_{0}=$ $-3,731$ e $\widehat{\sigma}=0,432$ no modelo múltiplo.

Visando uma melhor comparação de resultados, a regressão linear múltipla também foi adotada. Conforme apresentada na "Metodologia", a regressão logística usual e a regressão proposta com resposta contínua tem como premissa a consideração de um ponto de corte $(P N=2.500 \mathrm{~g})$ na análise de dados para o levantamento de fatores de risco para PN abaixo do ponto de corte pré-estabelecido. Na regressão linear, esse ponto de corte não é utilizado, ou seja, a variável resposta, PN, é analisada como um valor contínuo e a média do seu acréscimo ou decréscimo para cada condição (variável independente) é estimada. Dessa forma, pode-se obter resultados como quais fatores contribuiram para uma maior diminuição do PN. Utilizando o pacote de programas R, os resultados da regressão linear foram obtidos e apresentados na Tabela 5.

A Figura 8 apresenta alguns gráficos de diagnósticos de resíduos gerados durante a análise com a regressão linear. Nota-se uma distribuição satisfatoriamente normal para os resíduos, com variância constante. Pode-se notar também uma visível separação em dois grupos nos gráficos de resíduos. A presença dessa separação se deve à influência da variável "duração da gestação", a qual nitidamente separa a população em dois grupos com pesos ao nascer muito distintos (ver a Tabela 3). Devido a essa forte influência, foram 

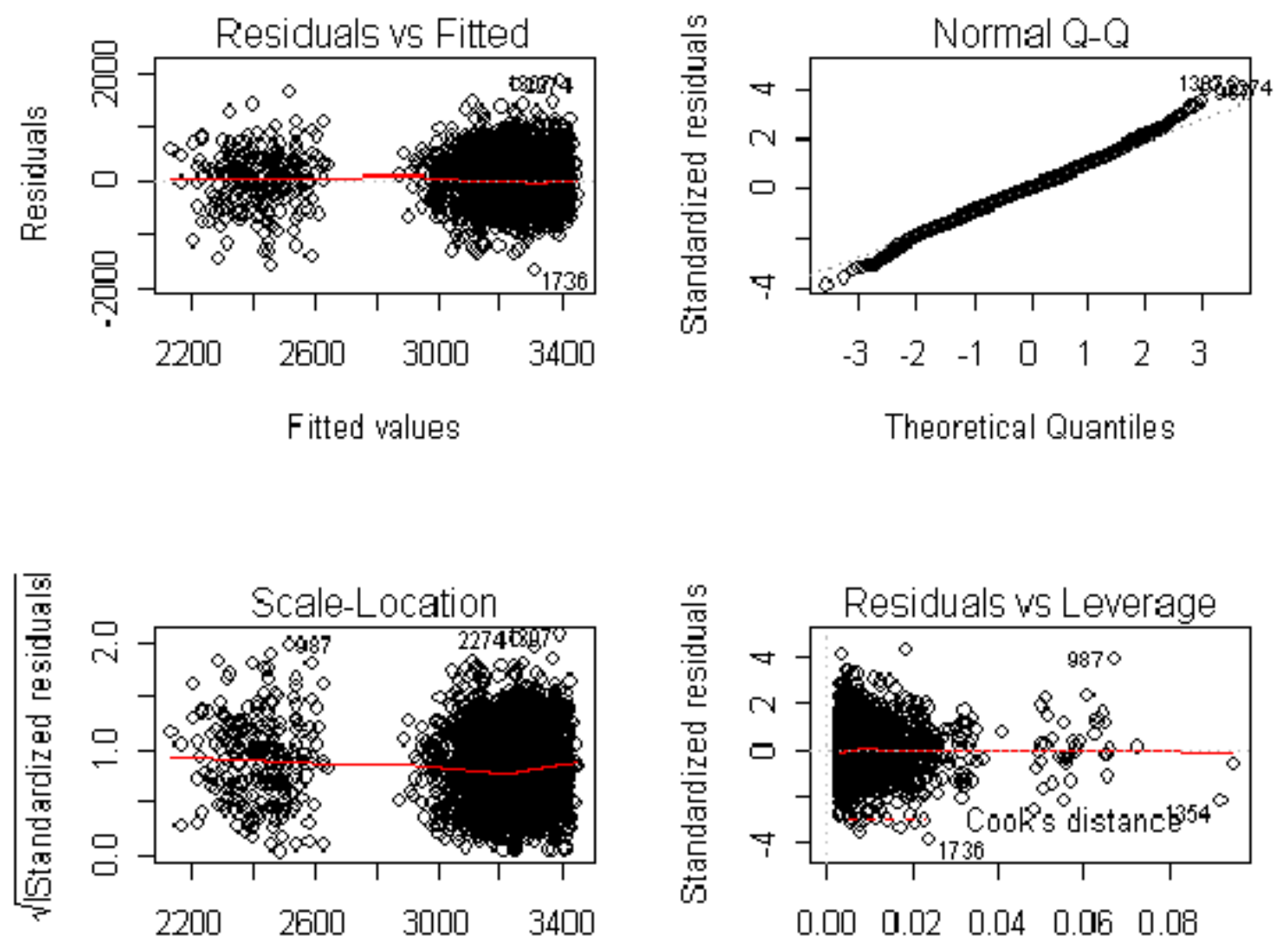

Figura 8: Gráfico de resíduos na análise de dados utilizando a regressão linear múltipla, SINASC - Ribeirão Preto (2005)

realizadas as mesmas análises com a regressão logística usual e a regressão com resposta contínua excluindo a variável "duração da gestação". A Tabela 6 apresenta os resultados desta análise.

Observando os resultados apresentados nas tabelas, pode-se concluir que na regressão logística usual, as exposições com evidências de associação com o BPN são: mãe viúva ou separada, mãe com 4 a 7 anos de estudo, duração da gestação de até 36 semanas, parto cesariano, menos que 7 consultas pré-natais, mãe com idade inferior a 15 anos, mãe primípara e sexo feminino. Na regressão linear, considerando o nível de significância de 5\%, as condições que contribuíram para um menor PN são: mãe com união consensual, duração de gestação abaixo de 36 semanas, participação de 1 a 6 consultas de pré-natal, 
Tabela 5: Resultados da regressão linear múltipla para dados do SINASC de Ribeirão Preto, 2005

\begin{tabular}{|c|c|c|c|}
\hline Variáveis & PN estimado $(g)$ & Erro padrão & p value \\
\hline Intercepto & $3.368,40$ & 52,29 & $<0,01$ \\
\hline \multicolumn{4}{|c|}{ Situação conjugal da mãe } \\
\hline Solteira & $-14,60$ & 20,01 & 0,466 \\
\hline Casada & ref. & ref. & ref. \\
\hline Viúva/Sep. & $-46,50$ & 56,83 & 0,413 \\
\hline União cons. & $-89,76$ & 40,07 & 0,025 \\
\hline \multicolumn{4}{|c|}{ Escolaridade da mãe (anos) } \\
\hline nenhuma & 36,47 & 102,97 & 0,723 \\
\hline 1 a 3 & 12,95 & 55,15 & 0,814 \\
\hline 4 a 7 & $-27,16$ & 27,20 & 0,318 \\
\hline 8 a 11 & $-38,71$ & 23,37 & 0,098 \\
\hline$\geq 12$ & ref. & ref. & ref. \\
\hline \multicolumn{4}{|c|}{ Duração da gestação (semanas) } \\
\hline até 36 & $-778,21$ & 31,20 & $<0,001$ \\
\hline$>36$ & ref. & ref. & ref. \\
\hline \multicolumn{4}{|c|}{ Tipo de parto } \\
\hline normal & ref. & ref. & ref. \\
\hline cesária & 9,54 & 19,52 & 0,625 \\
\hline \multicolumn{4}{|c|}{ Número de consultas pré-natal } \\
\hline nenhuma & $-166,66$ & 94,71 & 0,079 \\
\hline 1 a 3 & $-149,36$ & 43,52 & $<0,001$ \\
\hline 4 a 6 & $-123,68$ & 25,20 & $<0,001$ \\
\hline$\geq 7$ & ref. & ref. & ref. \\
\hline \multicolumn{4}{|l|}{ Raça / Cor } \\
\hline branca & 43,83 & 44,60 & 0,326 \\
\hline negra & ref. & ref. & ref. \\
\hline outras & 27,11 & 47,67 & 0,570 \\
\hline \multicolumn{4}{|c|}{ Idade materna (anos) } \\
\hline 10 a 15 & $-63,99$ & 66,85 & 0,338 \\
\hline 16 a 19 & $-9,62$ & 27,50 & 0,726 \\
\hline 20 a 29 & ref. & ref. & ref. \\
\hline 30 a 39 & $-10,30$ & 20,70 & 0,619 \\
\hline 40 a 49 & 16,63 & 57,34 & 0,772 \\
\hline \multicolumn{4}{|c|}{ É ou não primeiro filho } \\
\hline Sim & $-96,06$ & 19,32 & $<0,001$ \\
\hline Não & ref. & ref. & ref. \\
\hline \multicolumn{4}{|c|}{ Sexo do recém-nascido } \\
\hline Masculino & ref. & ref. & ref. \\
\hline Feminino & $-134,18$ & 17,14 & $<0,001$ \\
\hline
\end{tabular}


Tabela 6: Resultados da regressão logística e da regressão com resposta contínua para dados do SINASC de Ribeirão Preto excluindo a variável "duração da gestação", 2005.

\begin{tabular}{|c|c|c|c|c|}
\hline \multirow{2}{*}{ Variáveis } & \multirow{2}{*}{$\begin{array}{l}\text { Regressão logística } \\
\text { OR (IC 95\%) }\end{array}$} & \multicolumn{3}{|c|}{ Regressão com resposta contínua } \\
\hline & & $\ln (O R)$ & $\widehat{e p}$ & $O R(\mathrm{IC} 95 \%)$ \\
\hline \multicolumn{5}{|c|}{ Situação conjugal da mãe } \\
\hline Solteira & $1,03(0,71-1,48)$ & 0,028 & 0,089 & $1,03(0,85-1,20)$ \\
\hline Casada & ref. & ref. & ref. & 1,00 (ref.) \\
\hline Viúva/Sep. & $3,59(1,81-7,13)$ & 0,585 & 0,340 & $1,79(1,13-2,46)$ \\
\hline União cons. & $1,74(0,96-3,15)$ & 0,419 & 0,189 & $1,52(1,15-1,89)$ \\
\hline \multicolumn{5}{|c|}{ Escolaridade da mãe (anos) } \\
\hline nenhuma & $2,80(0,68-11,63)$ & $-0,086$ & 0,506 & $0,92(0,00-1,91)$ \\
\hline 1 a 3 & $1,50(0,56-4,01)$ & 0,086 & 0,259 & $1,09(0,58-1,60)$ \\
\hline 4 a 7 & $1,64(1,00-2,69)$ & 0,107 & 0,125 & $1,11(0,87-1,36)$ \\
\hline 8 a 11 & $1,30(0,83-2,02)$ & 0,172 & 0,106 & $1,19(0,98-1,40)$ \\
\hline$\geq 12$ & ref. & ref. & ref. & 1,00 (ref.) \\
\hline \multicolumn{5}{|c|}{ Tipo de parto } \\
\hline normal & ref. & ref. & ref. & 1,00 (ref.) \\
\hline cesária & $2,06(1,46-2,90)$ & 0,123 & 0,093 & $1,13(0,95-1,31)$ \\
\hline \multicolumn{5}{|c|}{ Número de consultas pré-natal } \\
\hline nenhuma & $7,70(2,72-21,84)$ & 1,246 & 0,482 & $3,48(2,53-4,42)$ \\
\hline 1 a 3 & $6,44(3,79-10,96)$ & 1,262 & 0,205 & $3,53(3,13-3,93)$ \\
\hline 4 a 6 & $3,05(2,10-4,45)$ & 0,797 & 0,120 & $2,22(1,98-2,45)$ \\
\hline$\geq 7$ & ref. & ref. & ref. & 1,00 (ref.) \\
\hline \multicolumn{5}{|l|}{ Raça / Cor } \\
\hline branca & $0,87(0,41-1,83)$ & $-0,098$ & 0,206 & $0,91(0,50-1,31)$ \\
\hline negra & ref. & ref. & ref. & 1,00 (ref.) \\
\hline outras & $1,13(0,52-2,47)$ & $-0,047$ & 0,220 & $0,95(0,52-1,39)$ \\
\hline \multicolumn{5}{|c|}{ Idade materna (anos) } \\
\hline 10 a 15 & $2,62(1,17-5,85)$ & 0,398 & 0,250 & $1,49(1,00-1,98)$ \\
\hline 16 a 19 & $1,02(0,64-1,62)$ & $-0,005$ & 0,128 & $0,99(0,74-1,25)$ \\
\hline 20 a 29 & ref. & ref. & ref. & 1,00 (ref.) \\
\hline 30 a 39 & $1,14(0,79-1,65)$ & 0,079 & 0,098 & $1,08(0,89-1,27)$ \\
\hline 40 a 49 & $1,58(0,67-3,76)$ & 0,104 & 0,308 & $1,11(0,51-1,71)$ \\
\hline \multicolumn{5}{|c|}{ É ou não primeiro filho } \\
\hline Sim & $1,72(1,21-2,43)$ & 0,474 & 0,090 & $1,61(1,43-1,78)$ \\
\hline Não & ref. & ref. & ref. & 1,00 (ref.) \\
\hline \multicolumn{5}{|c|}{ Sexo do recém-nascido } \\
\hline Masculino & ref. & ref. & ref. & 1,00 (ref.) \\
\hline Feminino & $1,46(1,08-1,97)$ & 0,554 & 0,080 & $1,74(1,58-2,05)$ \\
\hline
\end{tabular}


mãe primípara e recém-nascidos de sexo feminino. Já na regressão com resposta contínua, os resultados obtidos foram um pouco diferentes daqueles identificados pela regressão logística usual e pela regressão linear múltipla. Os fatores de risco associados ao BPN são: mãe no estado civil de união consensual, mãe com escolaridade entre 8 a 11 anos, duração da gestação de até 36 semanas, menos que 7 consultas pré-natais participadas, mãe primípara e bebês de sexo feminino. Comparando os resultados obtidos a partir dos modelos de regressão logística usual e com resposta contínua com a situação apresentada através dos box-plots, pode-se concluir que os dois modelos de regressão foram capazes de trazer resultados compatíveis aos informalmente evidenciados pelos box-plots. É possível perceber também que o método baseado em respostas contínuas estima intervalos de confiança com menor amplitude, evidenciando, dessa maneira, estimativas com maior precisão.

Perante a necessidade de comparação entre o desempenho do modelo usual e do modelo de resposta contínua baseado na distribuição normal em discriminar recém-nascidos em portadores ou não portadores de BPN, a curva ROC foi empregada, sendo a AUC considerada como o parâmetro de comparação das estimativas. Conforme a Equação 9, foi calculada a probabilidade de BPN para cada registro baseado nos seus valores para cada variável. A partir de pontos de corte estabelecidos sobre a amplitude destas probabilidades estimadas, foi calculada a sensibilidade e a especificidade, comparando os valores estimados e os pesos ao nascer reais.

A Figura 9 apresenta as curvas ROC na comparação de estimativa de parâmetros, utilizando o mesmo conjunto de dados da análise, ou seja, os 30\% dos registros totais, entre o método usual da regressão logística e o método baseado na regressão com resposta contínua ajustada na distribuição Gaussiana. Essa curva ROC foi elaborada utilizando o programa R, o qual também foi utilizado para calcular a respectiva AUC de cada curva. Para esse conjunto de dados, a curva ROC que representa o modelo da regressão logística usual possui uma AUC igual a 0,853. A AUC da curva ROC do modelo da regressão binária com resposta contínua é 0,838. Dessa forma, é possível concluir que, apesar de a 


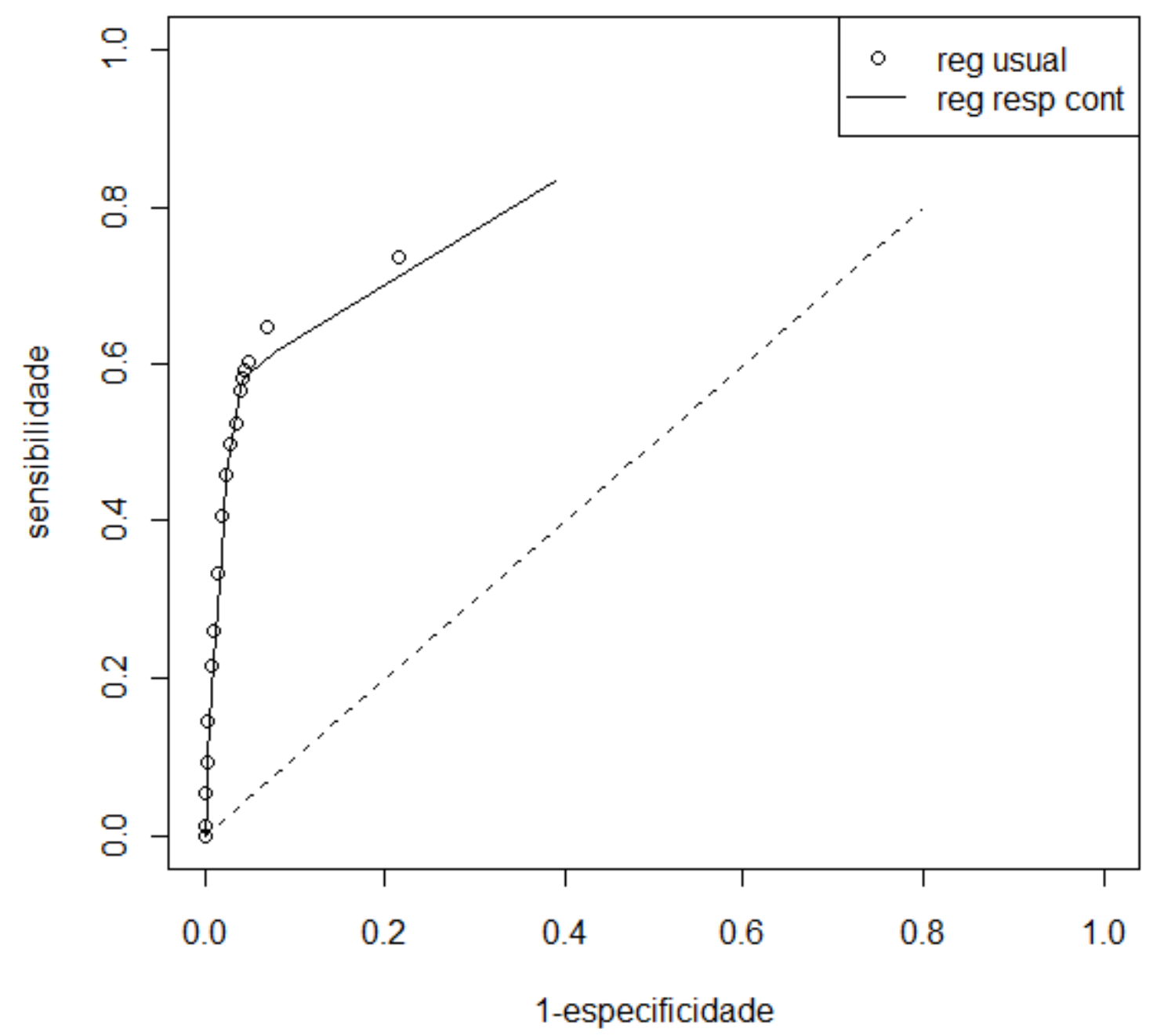

Figura 9: Curva ROC na comparação de métodos de estimativa com a regressão logística usual e a proposta no projeto. O mesmo conjunto de dados foi utilizado na estimativa e na obtenção da curva ROC 
regressão proposta possuir uma AUC ligeiramente inferior em relação à regressão logística usual, os dois modelos analisados apresentam bons desempenhos em relação à estimativa de parâmetros.

A Figura 10 apresenta a curva ROC efetuando a mesma comparação, mas utilizando os $70 \%$ dos dados restantes destinados ao teste de avaliação. Pode-se observar que as duas curvas ROC praticamente se sobrepõem, sugerindo então um desempenho muito próximo. A AUC da curva ROC para a regressão logística é 0,807 e a AUC da curva ROC que representa o modelo da regressão binária com resposta contínua é 0,813. Logo, o modelo proposto é ligeiramente superior em relação ao modelo usual quando necessitase "predizer"características de um conjunto desconhecido de dados. Além disso, a AUC obtida também revela que os dois modelos apresentam bons desempenhos na estimativa de parâmetros com dados desconhecidos.

Em suma, pode-se concluir que quando o mesmo conjunto de dados é utilizado na análise e no teste, o modelo proposto possui um bom desempenho, mas um pouco inferior se comparado à regressão logística. Em uma situação de inferência estatística, ou seja, na prática, ao se avaliar o desempenho dos métodos de estimativa num conjunto de dados desconhecidos, o método proposto ajustado à distribuição normal apresenta um desempenho preditivo superior à regressão logística usual.

Uma outra vantagem do método proposto sobre a regressão logística usual é em relação aos problemas de separação, os quais foram mencionados na Sub-seção 3.2. Durante o desenvolvimento do projeto, em algumas variáveis, ao se elaborar a tabela de frequência das suas categorias em relação ao percentual de BPN e pesos normais, ocorreu o problema da separação, especialmente quando o banco de dados é relativamente pequeno. Por exemplo, no banco de dados de 2005 do município de Ribeirão Preto (SP), nos dois casos totais de nascidos vivos com duração da gestação de 28 a 31 semanas, ambos nasceram com baixo peso e consequentemente ninguém nasceu com peso acima de $2.500 \mathrm{~g}$. Os mesmos problemas ocorreram ao analisar este conjunto de dados de Ribeirão Preto para as variáveis situação conjugal e raça. Esses problemas não são facilmente contornáveis 


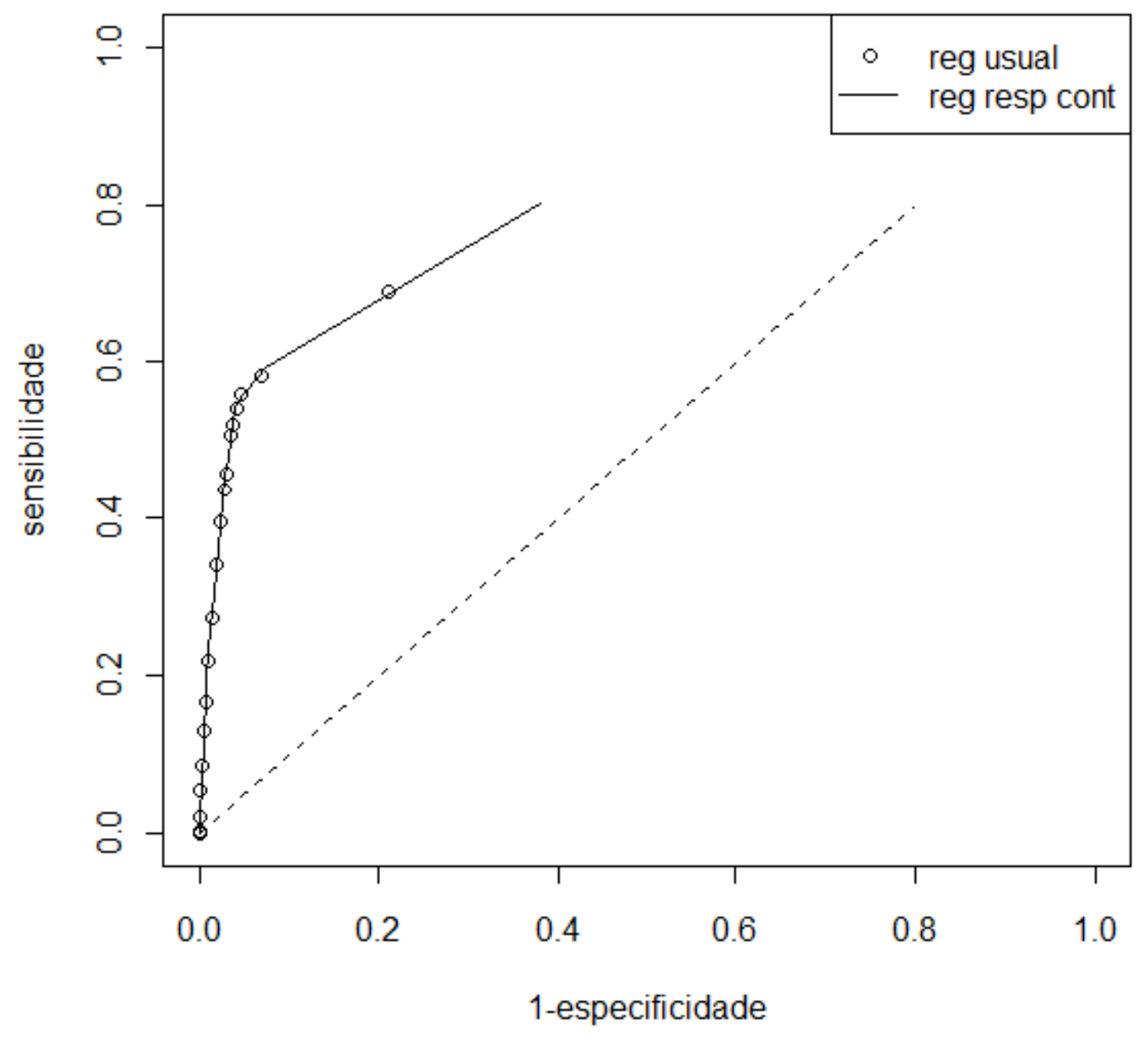

Figura 10: Curva ROC elaborada para a comparação entre a regressão usual e a proposta no projeto. A curva ROC foi obtida utilizando o conjunto de dados diferente daquele utilizado na estimação 
66

numa análise de regressão logística usual, mas não interferem na análise com o modelo de regressão aqui proposto, já que o $O R$ é calculado a partir do vetor $\beta$, este, por sua vez, é estimado utilizando o método de $M V$. 


\section{CONCLUSÃO}

Conforme citado no Capítulo 1, a prática da dicotomização das variáveis contínuas não é recomendada por muitos autores. Estes, baseado em vários tipos de estudos, apontaram que a categorização de variáveis originalmente contínuas pode trazer estimativas viciadas e o erro tipo $I$ inflacionado. Ao longo do desenvolvimento desta pesquisa, o modelo de regressão binária com resposta contínua foi estudado e implementado. Resultados obtidos a partir de modelos de regressão usuais, em especial, a regressão logística, e do modelo proposto neste projeto foram analisados e comparados. Pode-se notar que, em relação aos resultados obtidos a partir da regressão com resposta contínua, a regressão logística usual traz $O R$ s mais distantes do valor 1, o que sugere um erro tipo $I$ com maior probabilidade ao utilizar a regressão usual. Um outro resultado muito notável é refletido nas estimativas do intervalo de confiança para $O R$ obtidas a partir da regressão logística e da regressão com resposta contínua: o método de estimativa da MV utilizado na regressão binária com resposta contínua traz intervalos de confiança de menor amplitude.

A partir dos resultados obtidos ao investigar os principais fatores de risco para BPN, pode-se concluir que condições como estado conjugal da mãe, duração gestacional, participação de consultas pré-natais, primiparidade da mãe e sexo do $\mathrm{RN}$ influenciam no peso ao nascer da criança. Mães viúvas/separadas ou em união consensual, duração da gestação abaixo de 37 semanas, baixo número de consultas de pré-natal, mães primíparas e sexo feminino são alguns fatores associados ao BPN.

Ressalta-se que os resultados obtidos trazem algumas limitações. Um dos motivos que compromete a fidelidade dos resultados é a qualidade de dados oferecidos pelo SINASC. Erros de preenchimento de DN, treinamento insuficiente de profissionais no processo de preenchimento e omissões de registro podem ser as potenciais causas de comprometimento da qualidade do SINASC. Segundo Theme-Filha et al. (2004), em seu trabalho de investigação da confiabilidade e cobertura de registros de nascimentos provenientes do SINASC ocorridos no Município de Rio de Janeiro, algumas variáveis como número de filhos vivos e mortos possuem índice de subregistro relativamente alto e algumas variáveis como esco- 
laridade materna, situação conjugal e número de consultas pré-natais apresentam índices de concordância relativamente mais baixos. Os dados do Município de Ribeirão Preto utilizados na presente pesquisa possuem seu maior índice de subregistro na variável "etnia". Não foi possível obter conclusões evidentes sobre a confiabilidade dos dados do SINASC utilizados. Há possibilidades de registros errôneos, pois foram observados vários registros cujas variáveis assumirem valores não definidos pelo manual de preenchimento do SINASC. 


\section{TRABALHOS FUTUROS}

Posteriormente, os seguintes trabalhos poderão ser realizados:

a) Implementação de diferentes funções de ligação para o modelo de regressão binária com resposta contínua, pois poderão trazer interpretações mais adequadas aos dados de acordo com o que se objetiva em sua análise. Comparações entre modelos utilizando essas diferentes funções de ligação serão baseadas em medidas como o AIC, BIC ou estatísticas de razão de verossimilhanças. Ao se utilizar amostras grandes, o BIC poderá trazer melhores comparações já que é considerado o tamanho amostral em seu termo de penalidade.

b) Ajustar o modelo proposto em outras funções de distribuição. Entre elas, destaca-se a distribuição log-normal.

c) Realização de mais testes de simulação baseados em Monte Carlo em cadeia de Markov (MCMC) para comparação de resultados entre a regressão logística e a regressão proposta, já que esta oferece $I C$ de menor amplitude, resultado extremamente vantajoso se o mesmo apresentar igual desempenho de estimação em relação à regressão logística usual.

d) Implementação de um modelo Bayesiano, que poderá trazer como vantagem maior robustez em relação ao pressuposto de normalidade (ou outra distribuição) dos dados originais. Essa comparação pode utilizar o critério DIC (Deviance Information Criterion, ver SPIEGELHALTER et al., 2002) ou fator de Bayes. Ao ajustar versões do modelo com estimação Bayesiana dos parâmetros, as propriedades de robustez poderão ser verificadas pela escolha de bancos de dados com distribuições da variável resposta com forma bastante distinta da normal ou através de perturbações no banco de dados. Em outras palavras, comparações entre diferentes modelos clássicos utilizam frequentemente os critérios de informação AIC, BIC ou outras idéias baseadas em somas de quadrados de resíduos, enquanto comparações entre modelos Bayesianos frequentemente baseiam-se no critério DIC ou no fator de Bayes. Entretanto, não há critérios objetivos que comparem diretamente modelos clássicos e Bayesianos, e a introdução de algum critério direto de 
comparação pode ser bastante subjetiva, dado que, a princípio, um modelo Bayesiano pode trazer sempre menores somas de quadrados de resíduos se utilizadas distribuições a priori suficientemente informativas. A possibilidade de introduzir elementos subjetivos em uma abordagem Bayesiana a partir das distribuições a priori, é obstáculo à busca de medidas ou índices que comparem modelos clássicos e Bayesianos. Desta maneira, em um estudo futuro, modelos clássicos e Bayesianos não serão comparados objetivamente por critérios de informação (como AIC, BIC ou DIC), mas pretende-se contrapor as estimativas fornecidas por ambas as abordagens em situações nas quais a distribuição da variável resposta afasta-se da distribuição de normalidade ou onde existam valores bastante atípicos, o que equivale a demonstrar que a abordagem Bayesiana traz propriedades de robustez mais satisfatórias. 


\section{REFERÊNCIAS}

AKAIKE, H. A new look at the statistical model identification. IEEE Transactions on Automatic Control. 1974; 19 (6): 716-723.

ALBERT, A.; ANDERSON, J. A. On the existence of maximum likelihood estimates in logistic regression models. Biometrika. 1984; 71:1-10.

ALTMAN,DG; ROYSTON, P. The cost of dichotomising continuous variables. British Medical Journal. 2006; 332:1080.

APGAR, V. A proposal for a new method of evaluation of the newborn infant. Current Researches in Anesthesia \& Analgesia. 1953; 32: 260-267.

AQUINO-CUNHA, M.; QUEIROZ-ANDRADE, M.; TAVARES-NETO, J.; ANDRADE, T. Gestação na adolescência: Relação com o baixo peso ao nascer. Revista Brasileira de Ginecologia e Obstetrícia 2002; 24 (8): 513-519.

ARAÚJO, A. R. Regressão logística com resposta contínua. Dissertação de Mestrado. São Paulo, 2002. Instituto de Matemática e Estatística da Universidade de São Paulo (IME/USP).

AUSTIN, P. C.; BRUNNER L. J. Inflation of the type I error rate when a continuous confounding variable is categorized in logistic regression analyses. Statistics in Medicine. 2004, Apr 15; 23(7):1159-1178.

CARNIEL, E. F.; MONTEIRO-ANTÔNIO, M. A. R. G.; LIMA e MOTA, M. R. M.; MORCILLO, A. M.; ZANOLLI, M. L. A "Declaração de Nascido Vivo" como orientadora de ações de saúde em nível local. Revista Brasileira de Saúde Materna e Infantil. Recife, 2003; 3 (2): 165-174.

CARVALHO, D. M. Grandes sistemas nacionais de informação em saúde: Revisão e discussão da situação atual. Informe Epidemiológico do SUS. 1997; 5 (4): 7-46.

CASCAES, A. M.; GAUCHE, H.; BARABARCHI, F.M.; BORGES, C.M.; PERES, K.G. Prematuridade e fatores associados no Estado de Santa Catarina, Brasil, no ano de 2005: análise dos dados do Sistema de Informações sobre Nascidos Vivos. Cadernos de Saúde Pública, Rio de Janeiro, 2008; 24(5): 1024-1032.

CASELLA, G.; BERGER, R. L. Statistical Inference. 2nd. Ed. Duxbury Press, 2001.

CHEN, H.; COHEN, P.; CHEN, S. Biased odds ratios from dichotomization of age. Statistics in Medicine, 2007, Aug; 15; 26 (18): 3487-3497.

COLLINSON, P. OF BOMBERS. Radiologists, and cardiologists: time to ROC. Heart. $1998 ; 8(3):$ 215-217.

COSTA, C. E.; GOTLIEB, S. L. D. Estudo epidemiológico do peso ao nascer a partir da Declaração de Nascido Vivo. Revista de Saúde Pública. 1998; 32 (4): 328-334. 
CUMSILlE, F.; BANGDIWALA, S. J.; SEN, P. K.; KUPPER, L. L. Effect of dichotomizing a continuous variable on the model structure in multiple linear regression models. Communications in Statistics, Theory and Methods. 2000; 29 (3): 643654 .

DATASUS. Disponível em: <http://www.datasus.gov.br/DATASUS >. Acesso em: $27 / 12 / 2010$.

GAMA, S. G. N.; SZWARCWALD, C. L.; LEAL, M. C.; THEME-FILHA, M. M. Gravidez na adolescência como fator de risco para baixo peso ao nascer no município do Rio de Janeiro, 1996 a 1998. Revista de Saúde Pública. 2001; 35 (1): 74-80.

GAMA, S. G. N.; SZWARCWALD, C. L.; SABROZA, A. R.; BRANCO, V. C.; LEAL, M. C. Fatores associados à assistência pré-natal precária em uma amostra de puérperas adolescentes em maternidades do município do Rio de Janeiro, 1999-2000. Cadernos de Saúde Pública, Rio de Janeiro, 20 Sup 1:S101-S111, 2004.

GIGLiO, M. R. P.; LAMOUNIER, J. A.; MORAIS-NETO, O. L.; CÉSAR, C. C. Baixo peso ao nascer em coorte de recém nascidos em Goiânia-Brasil no ano de 2000. Revista Brasileira de Ginecologia e Obstetrícia. 2005; 27 (3): 130-136.

GUERRA, A.F.F.S.; HEYDE, M.E.D.;MULINARI, R.A. Impacto do estado nutricional no peso ao nascer de recém-nascidos de gestantes adolescentes. Revista Brasileira de Ginecologia e Obstetrícia. 2007; 29(3): 126-133

HERITER, S.; RONCHETTI, E. Robust binary regression with continuous outcomes. The Canadian Journal of Statistics. 2004; 32 (3): 239-249.

HOSMER, D. W.; LEMESHOW, S. Apllied Logistic Regression. 2nd. Ed. New York: John Wiley \& Sons, 2000.

IHE: Institute of Health Economics. Determinants and prevention of low birth weight: a synopsis of the evidence. IHE Report. 2008, Dec.

KILSZTAJN, S.; SOUZA-LOPES, E.; CARMO, M. S. N.; ANDRADE-REYES, A. M. Vitalidade do recém-nascido por tipo de parto no estado de São Paulo, Brasil. Cadernos de Saúde Pública. Rio de Janeiro, 2007; 23 (8): 1886-1892.

LESAFFRE, E.; ALBERT, A. Partial separation in logistic discrimination. Journal of the Royal Statistical Society, Series B, 1989; 51:109-116.

MARTINEZ, Z. E.; LOUZADA-NETO, F.; PEREIRA, B. B. A curva ROC para testes diagnósticos. Cadernos Saúde Coletiva, Rio de Janeiro, 2003; 11 (1): 7-31.

MELLO-JORGE, M. H. P.; GOTLIEB, S. L. D.; OLIVEIRA, H. O Sistema de Informações sobre Nascidos Vivos: primeira avaliação dos dados brasileiros. Informe Epidemiológico do SUS. Brasília, 1996; 4 (2): 15-48.

MOSER, B. K.; COOMBS, L. P. Odds ratios for a continuous outcome variable without dichotomizing. Statistics in Medicine 2004 Jun 30; 23 (12):1843-1860. 
MURATA, M.K.; SCHIMARELLI, G.T.; SFENDRYCH, R.R.; et al. Gravidez na adolescência: estudo epidemiológico no Hospital Evangélico de Curitiba. ACM: Arquivos Catarinenses de Medicina 1998; 27:19-24.

NEME, B. Obstetrícia Básica. Edit. Sarvier, São Paulo, 1994.

NETO, O. L. M; BARROS, M. B. A. Fatores de Risco para Mortalidade Neonatal e Pós-Neonatal na Região Centro-Oeste do Brasil: linkage entre bancos de dados de nascidos vivos e óbitos infantis. Cadernos de Saúde Pública, Rio de Janeiro, 2000; 16(2): 477-485.

PAGAnO, M; GAUVREAU, K. Princípios de Bioestatística. 2nd. Ed. São Paulo: Thomson Learning, 2006.

RAGLAND, D. Dichotomizing continuous outcome variables: dependence of the magnitude of association and statistical power on the cutoff point. Epidemiology 1992; 3: 434-440.

RIPSA - Rede Interagencial de Informações para a Saúde. Indicadores básicos de saúde no Brasil: conceitos e aplicações. Brasília. Organização Pan-Americana da Saúde. 2002.

ROTH, J; HENDRICKSON, J; STOWELL, D.W. The risk of teen mothers having low birth weight babies: implications of recent medical research for school health personnel. Journal of School Health 1998; 68: 271-275.

ROYSTON, P.; ALTMAN, D. G.; SAUERBREI, W. Dichotomizing continuous predictors in multiple regression: a bad idea. Statistics in Medicine. 2006; 25: 127-141.

SAS - BUSINESS ANALYTICS AND BUSINESS INTELIGENCE. Disponível em: $<$ http://www.sas.com/>. Acesso em: 27/12/2010.

SILVA, C. A. M. Exploração de métodos de seleção de variáveis pela técnica de regressão logística para análise de dado epidemiológicos. Dissertação de Mestrado. Campinas, 2006. Faculdade de Ciências Médicas da Universidade Estadual de Campinas.

SOUZA, M. F. M.; CORDEIRO, L. D.; OLIVEIRA, G. J. S.; FILHO, A. M. S.; MALTA, D. C.; MANSANO, N. H.; DUARTE, E. C.; ALVES, A. C.; CARMO, E. H.; LUNA, E.; DOMINGUEZ, C. M. A. S.; SILVA-JR., J. B. Saúde Brasil 2004: uma análise da situação de saúde. Secretaria de Vigilância em Saúde / MG.

SCHWARZ, G. Estimating the dimension of a model. Annals of Statistics. 1978; $6(2): 461-464$.

SPIEGELHALTER, D. J.; BEST, N. G.; CARLIN, B. P.; VAN DER LINDE, A. Bayesian measures of model complexity and fit (with discussion). Journal of the Royal Statistical Society, October, 2002. Series B (Statistical Methodology), 64(4): 583-639. 
SUISSA, S. Binary methods for continuous outcomes: a parametric alternative. Journal of Clinical Epidemiology. 1991; 44 (3): 241-8.

SUISSA, S.; BLAIS L. Binary regression with continuous outcomes. Statistics in Medicine. 1995; 14(3): 247-55.

SZWARCWALD, C. L.; LEAL, M. C.; ANDRADE, C. L. T. SOUZA-JR., P. R. B. Estimação da mortalidade infantil no Brasil: o que dizem as informações sobre óbitos e nascimentos do Ministério da Saúde?. Cadernos de Saúde Pública. Rio de Janeiro, $2002 ; 18$ (6): 1725-36.

THEME-FILHA, M. M.; GAMA, S. G. N.; CUNHA, C. B.; CARMO-LEAL, M. Confiabilidade do Sistema de Informações sobre Nascidos Vivos hospitalares no município do Rio de Janeiro, 1999-2001. Cadernos de Saúde Pública. Rio de Janeiro, 2004; 20 Sup (1): S83-S91.

THE R PROJECT FOR STATISTICAL COMPUTING. Disponível em: < http://www.rproject.org/>. Acesso em: 27/12/2010.

VIACAVA, F. Informações em saúde: a importância dos inquéritos populacionais. Ciência \& Saúde Coletiva. 2002; 7 (4): 607-621.

WHO - World Health Organization. Expert group on prematurity. Final report. In: WHO Technical Report, n 27. Geneva: WHO, 1950.

WHO - World Health Organization. Informatics and telematics in health: present and potential uses. Geneva: WHO; 1988. ISBN 9241561173.

WHO - World Health Organization. Newborn health and survival: a call to action. In: Family and Community Health. Geneva: WHO; 2001.

WHO - World Health Organization. Physical status: the use and interpretation of anthropometry. In: WHO - Technical Report, nº 854. Geneva: WHO, 1995.

WHO - World Health Organization. The incidence of low birth-weight: a critical review of available information. World Health Statistics Quartely. 1980;33(3):197224.

ZHAO, P. L.; KOLONEL, L. N. Efficiency loss from categorizing quantitative exposures into qualitative exposures in case-control studies. American Journal of Epidemiology 1992; 136: 464-474. 
ANEXO A- Ofício de aprovação do Comitê de Ética em Pesquisa 
Oficio $n^{\circ} 2324 / 2009$

$\mathrm{CEP} / \mathrm{MGV}$

Prezados Senhores,

O trabalho intitulado "PROPOSTA DE UM MODELO DE REGRESSÃO BINÁRIA COM RESPOSTA CONTÍNUA APLICADO À ANÁLISE DOS DADOS DO 'SINASC: IDENTIFICAÇÃO DE FATORES DE RISCO PARA O BAIXO PESO AO NASCER" foi analisado pelo Comitê de Ética em Pesquisa, em sua $291^{\text {a }}$ Reunião Ordinária realizada em 20/07/2009 e enquadrado na categoria: APROVADO, de acordo com o Processo HCRP n 5934/2009.

Este Comitê segue integralmente a Conferência Internacional de Harmonização de Boas Práticas Clinicas (IGH-GCP), bem como a Resolução no 196/96 CNS/MS.

Lembramos que devem ser apresentados a este CEP, o Relatório Parcial e o Relatório Final da pesquisa. Atenciosamente.

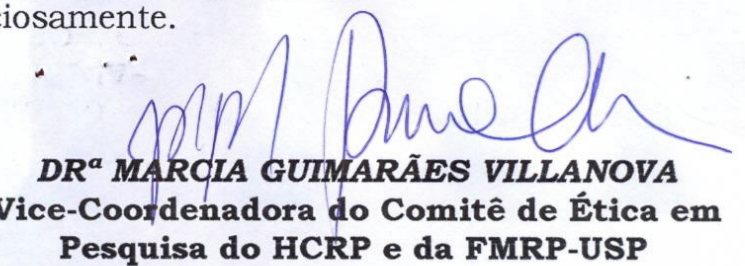

Ilustríssimos Senhores

WU ZHUOFAN

PROF. DR. EDSON ZANGIACOMI MARTINEZ (Orientador)

Depto. de Medicina Social

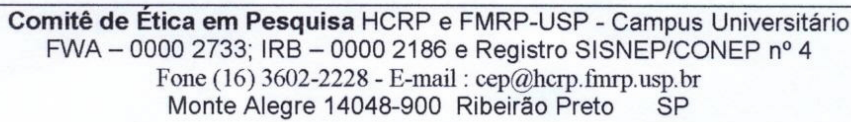

